\title{
Effects of Hydrothermal Conditions on the Net Primary Productivity in the Source Region of Yangtze River, China
}

Zhe Yuan ( $\square$ yuanzhe_0116@126.com )

Changjiang River Scientific Research Institute https://orcid.org/0000-0001-8525-2415

\section{Yongqiang Wang}

Changjiang River Scientific Research Institute

Jijun Xu

Changjiang River Scientific Research Institute

Jun Yin

Hubei University

\section{Shu Chen}

Changjiang River Scientific Research Institute

\section{Research}

Keywords:

Posted Date: February 26th, 2020

DOI: https://doi.org/10.21203/rs.2.24647/v1

License: (9) This work is licensed under a Creative Commons Attribution 4.0 International License. Read Full License 


\section{Effects of Hydrothermal Conditions on the Net Primary Productivity in the Source Region of Yangtze River, China}

\section{Zhe Yuan ${ }^{1, *}$, Yongqiang Wang', , Jijun Xu ${ }^{1}$, Jun Yin ${ }^{2}$, Shu Chen ${ }^{1}$}

1 Changjiang River Scientific Research Institute, Changjiang Water Resources Commission of the Ministry of Water Resources of China, Wuhan, China;

2 Faculty of Resources and Environmental Science, Hubei University, Wuhan, China.

* Correspondence: Zhe Yuan, yuanzhe_0116@126.com; Yongqiang Wang, wangyq@mail.crsri.cn

\section{Abstract}

Background: The ecosystems and natural environment of the Source Region of Yangtze River (SRYR) is highly susceptible to the climate change. Quantifying the response of vegetation Net Primary Productivity (NPP) to the changes of hydrothermal conditions is an important way to identify and predict global ecosystem dynamics.

Methods: Using MODIS/Terra Yearly NPP data at $1 \mathrm{~km} \times 1 \mathrm{~km}$ spatial resolution, the spatial-temporal variation of NPP was analyzed at first. Then, correlations between NPP and hydrothermal conditions were evaluated with soil water content and accumulated temperature. Finally, a response model was built to analyze the sensitivity of the NPP to precipitation and temperature changes.

Result: (1) NPP is generally lower in the western SRYR and increases gradually toward the east, with an average value of $85.2 \mathrm{gC} / \mathrm{m}^{2}$. The total NPP had increased by $1.42 \mathrm{TgC}$ per year from 2000 to 2014 . The fastest change rate of NPP is presented in the Downstream region, followed by the middle stream region and Dam River Basin; (2) the NPP of one specific year has obvious relationship with the accumulated temperature of the same year and the soil water deficit of the previous year. The temperature is the dominant climate factor impacting vegetation growth in the SRYR; (3) It is shown an increase of NPP by $0.194 \mathrm{TgC}$ (nearly $30 \%$ ) with a $1-^{\circ} \mathrm{C}$ increase in annual mean temperature. While a $10 \%$ increase in annual precipitation corresponds to an increase in NPP by $0.517 \mathrm{TgC}$ (nearly $5 \%)$.

Conclusion: A warming, wetting and greening SRYR was detected in recent decade. The NPP in SRYR is more sensitive to changes in temperature than changes in precipitation.

30 Keywords: Source Region of Yangtze River; NPP; Hydrothermal conditions; Spatial-temporal variation; Correlation and sensitivity

\section{Introduction}

Net primary productivity (NPP) is defined as the net amount of carbon taken in by plants via photosynthesis, and is equal to the difference between the carbon assimilated during photosynthesis and that released during plant respiration (Leith 1975; Goldewijk and Leemans, 1995). It is an important index for evaluating the health and the carbon cycling of terrestrial ecosystems (Beerling and Osborne, 2006; Haberl and Fischer Kowalski 2007; Frank et al., 2015). 
ecosystem attributes and human activities. Among these factors, climatic conditions have been proven to be the dominating one (Zhou and Zhang 1996; Nemani et al., 2003; Beerling and Osborne, 2006; Frank et al., 2015). The NPP has been significantly influenced by rising temperature and redistributed precipitation patterns in recent decades. The global NPP increased by $0.19 \mathrm{PgC}$ per year from 1982 to 1999 (Nemani et al.,2003). And an increase of $0.03 \mathrm{PgC}$ per year was found over the 15 years, between 2000 and 2014 (Tum et al., 2016). It is difficult to infer that the increasing trend has begun to slow down since 2000, because the simulation models used in the above studies were different. But the global NPP showed increase trend with some fluctuation in both periods. In China, the total NPP increased by 1.90\% from the 1980s to 2015. The Huang-Huai-Hai Region has witnessed the largest increase in total NPP, followed by Loess Plateau Region and Northeast China Region ( $\mathrm{Li}$ et al., 2018). However, there still exist uncertainties in the NPP trend, deriving from complicated mechanism of NPP change (Ahlström et al., 2012).

The research on relationship between climate variables (or hydrothermal conditions) and NPP at the regional and global scales has great importance in the ecological field. With remote sensing applications or process-based modeling techniques, the effects of climate change (or hydrothermal conditions change) on vegetation have been explored in the worldwide (Mohamed, et al., 2004; Motew and Kucharik, 2013; Jin et al.,2018; Tripathi, et al., 2019; Zheng et al.,2020). Specifically, a series of ecological indicators including NPP at regional scales can be obtained from the Moderate Resolution Imaging Spectroradiometer (MODIS) (Justice et al., 1998). These systematic geospatial products can reveal continuous spatio-temporal patterns, making it widely used. Previous studies have proven that the variability of terrestrial NPP has relation with both temperature and precipitation (Mohamed, et al., 2004; Piao et al., 2011; Li et al.,2018; Wang et al., 2018). But primary climate factors affected the NPP differently in diverse regions. Generally, terrestrial NPP is more susceptible to temperature in middle and high latitudes while precipitation is the dominating factor in low latitudes (Gang et al., 2015). However, some aspects of these relationships remain to be further studied and discussed, mainly due to the differences in study areas and study time periods.

The Source Region of Yangtze River (SRYR) is a typical alpine region in the western Tibetan plateau, situated at $4000 \mathrm{~m}$ above mean sea level. It is referred to as an important ecological security shelter zone in Three-River Headwaters region. However, The SRYR's ecosystems and natural environment are inherently fragile and vulnerable to global warming. Similar to the whole Tibetan plateau, the SRYR has experienced significant warming trends in recent decades. The temperature increased by $0.34^{\circ} \mathrm{C} / 10 \mathrm{a}$ during the period from 1957 to 2013 (Du et al., 2017) and this warming is predicted to continue in the next 30 years based on CMIP5 Climate Models (Yuan et al., 2019). It is necessary to observe the vegetation and analyze the climate change in this significant place. This research took the SRYR as the study area and explored the effects of hydrothermal condition on NPP. In this study, the hydrothermal conditions refer to soil water content and accumulated temperature, which can be obtained from meteorological data and the NPP data came from MOD17A3 products. Both the correlations between NPP and hydrothermal condition, and sensitivity of NPP to climate change were analyzed in this paper. 


\section{Study area and data}

\subsection{Study area}

The Source Region of Yangtze River (SRYR for short, Latitude: $32^{\circ} 25^{\prime} \mathrm{E}$ and $35^{\circ} 53^{\prime} \mathrm{E}$; Longitude: $89^{\circ} 43^{\prime} \mathrm{E}$ to $97^{\circ} 19^{\prime} \mathrm{E}$ ), located in the western Tibetan plateau, covers an area of 159,065 $\mathrm{km}^{2}$ (Fig.1). The elevation ranges from $6,456 \mathrm{~m}$ in the West to $3,512 \mathrm{~mm}$ in the East, with an average of $4,779 \mathrm{~m}$. The average annual precipitation is approximately $327.4 \mathrm{~mm}$, which is mainly distributed from June to September. The average annual temperature is about -5.5 to $3.0^{\circ} \mathrm{C}$ from northeast to southwest, with an average of $2.9^{\circ} \mathrm{C}$ (Chen, 2013; Du et al., 2017). The aridity index is 3.67 in the SRYR, which means the climate is very dry. The land cover in the SRYR consists primarily of grasslands (63.8\%) and unused land (29.4\%). Water area and forest land are less dominant land cover types, accounting for $6.5 \%$ and $0.3 \%$ of the total area of SRYR. Due to the cold and dry climatic conditions, the eco-hydrology process of the whole region is sensitive to climate change.

\section{[Figure 1]}

\section{Fig.1 The location of Source Region of Yangtze River (SRYR)}

\subsection{Datasets}

\subsubsection{Remote sensing data}

Remote sensing data used are obtained from global annual MOD17A3 products (version: 055) from 2000 to 2014, and all of them have a spatial resolution of $1 \mathrm{~km}$. This dataset is produced by the Numerical Terradynamic Simulation Group (NTSG) at the University of Montana (UMT) (available from https://earthdata.nasa.gov/).

\subsubsection{Meteorological data}

The gridded meteorological data used are obtained from China Ground Precipitation $0.5^{\circ} \times 0.5^{\circ}$ Grid Dataset V2.0 and China Ground Temperature $0.5^{\circ} \times 0.5^{\circ}$ Grid Dataset V2.0. These datasets are provided by National Meteorological Information Center (http://data.cma.cn/). A total of 102 grids in the SRYR and the surroundings during 2000 to 2014 are selected. The gridded data has been projected and resampled in order to ensure the same coordinate system and resolution with MOD17A3 products.

\section{Methodology}

\subsection{Calculation of soil water deficit and accumulated temperature}

\subsubsection{Soil water deficit}

Soil water content is one of limiting factors for vegetation growth, especially in arid and 
semi-arid regions (e.g. the SRYR). In this study, we used soil water deficit to represent the soil water content, which can be calculated according to the following function:

$$
S D=P-R-P E
$$

where, $S D$ is the annual soil water deficit $(\mathrm{mm}) ; P$ is the annual precipitation $(\mathrm{mm}) ; R$ is the annual surface runoff ( $\mathrm{mm}) ; P E$ is the annual land-surface evaporation $(\mathrm{mm})$.

Annual surface runoff $(R)$ can be obtained from the runoff coefficient $(\alpha)$ and annual precipitation $(P)$ according to Eq.2. The USDA-SCS method and the experience value method was

Table 1 Runoff coefficients for different slopes used for determining the runoff coefficients in this study (Zhang, 2010) (Table 1).

$$
R=\alpha P
$$

\section{[Table 1]}

Takahashi Koichiro Lang Equation (Takahashi, 1979) was selected to estimate $P E$ in Eq.1, which is a widespread application for its simple structure (Eq.3).

$$
P E_{m}=\frac{3100 P_{m}}{3100+1.8 P_{m}^{2} \exp \left(-\frac{34.4 T_{m}}{235.0+T_{m}}\right)}
$$

where, $P E_{m}, P_{m}$ and $T_{m}$ are monthly land-surface evaporation ( $\mathrm{mm}$ ), monthly precipitation ( $\mathrm{mm}$ ) and monthly temperature $\left({ }^{\circ} \mathrm{C}\right)$, respectively.

\subsubsection{Accumulated temperature}

Accumulated temperature refers to the sum of daily mean temperatures greater than or equal to a critical temperature (here is $0^{\circ} \mathrm{C}$ ), which can be calculated by the following formula:

$$
A T 0=\sum_{i=D_{b}}^{D_{e}} T_{i} \quad T_{i} \geq 0
$$

where, $A T 0$ is the $\geq 0^{\circ} \mathrm{C}$ accumulated temperature ( $\left.\mathrm{mm}\right) ; T_{i}$ is the daily mean temperature on day $i$;

$134 D_{b}$ and $D_{e}$ are the beginning date and ending date with $T \geq 0^{\circ} \mathrm{C}$ in each year of Julian calendar,

135 which can be determined with 5-day moving average method (Yan et al., 2011; Zhang et al., 136 2011).

\section{$137 \quad 3.2$ Trend and correlation analysis}

\section{$138 \quad 3.2 .1 \quad$ Linear regression and the slope}

139 To identify the inter-annual trends of NPP, soil water deficit and accumulated temperature, 140 the linear regression method was adopted to eliminate the increase or decrease rate (Tian et al. 141 2019), which can be calculated as follows: 


$$
\theta_{\text {Slope }}=\frac{n \times \sum_{i=1}^{n}\left(i \times X_{i}\right)-\sum_{i=1}^{n} i \sum_{i=1}^{n} X_{i}}{n \times \sum_{i=1}^{n} i^{2}-\left(\sum_{i=1}^{n} i\right)^{2}}
$$

143 where, $\theta_{\text {slope }}$ is the linear slope of the time series variable, which can be used to characterize the increase or decrease rate during a given study period; $n$ is the number of years (here $n=15$ ); $X_{i}$ is the NPP, soil water deficit or accumulated temperature for the $i$ th year $(i=1,2, \ldots n)$.

\subsubsection{Mann-Kendall trend test}

A nonparametric test, Mann-Kendall (M-K) trend analysis (Mann, 1945; Kendall, 1948) was utilized to test the tendency of NPP, soil water deficit and accumulated temperature in the SRYR.

The test statistic $Z$ is calculated as follows:

$$
Z=\left\{\begin{array}{cc}
\frac{S-1}{\sqrt{\operatorname{Var}(S)}} & S>0 \\
0 & S=0 \\
\frac{S+1}{\sqrt{\operatorname{Var}(S)}} & S<0
\end{array}\right.
$$

where, $|Z|=1.65$ and $|Z|=1.96$ indicate the critical values at the significance levels of $p=0.1$ and 0.05 , respectively; in variance $\operatorname{Var}(S)=n(n-1)(2 n+5) / 18, n$ is the number of years (here $n=15$ ); statistical variable $S$ can be calculated by Eq.7 and Eq.8.

$$
S=\sum_{k=1}^{n-1} \sum_{j=k+1}^{n} \operatorname{Sgn}\left(X_{j}-X_{k}\right)
$$

where, $X_{j}$ and $X_{k}$ are variables (NPP, $S D$ or $A T 0$ ) for the $j$ th year and $k$ th year respectively.

\subsubsection{Correlation coefficient}

To assess the effects of soil water deficit and accumulated temperature on NPP in the SRYR, correlation coefficient $R$ was employed to analyze the correlation between two variables (NPP vs. $S D, N P P$ vs. $A T 0$ ), using the following formula: 


$$
R_{X Y}=\frac{\sum_{i=1}^{n}\left(X_{i}-\bar{X}\right)\left(Y_{i}-\bar{Y}\right)}{\sqrt{\sum_{i=1}^{n}\left(X_{i}-\bar{X}\right)^{2}} \sqrt{\sum_{i=1}^{n}\left(Y_{i}-\bar{Y}\right)^{2}}}
$$

where, $Y$ denotes the NPP and $X$ denotes the $S D$ or $A T 0 .|R| \geq 0.8,0.5 \leq|R|<0.8,0.3 \leq|R|<0.5$ and $|R|$ $<0.3$ represent high correlation, significant correlation, low correlation and weak correlation respectively.

\subsection{Response model of NPP to hydrothermal conditions and sensitivity analysis}

\subsubsection{Response model built by multiple linear regressions}

It is complex to explain how vegetation respond to hydrothermal conditions. Previous studies have found that there is relationship between NPP and precipitation and temperature (Li et al., 2018; Byrne et al.,2013; Gao et al., 2009). In addition, several studies have found time lags in vegetation growth responding to precipitation (Nezlina et al., 2005; Bajgiran et al., 2008). Then, it may be a reasonable approach to establish a model based on the statistical relation between NPP of one specific year $\left(N P P_{i}\right)$ with the accumulated temperature of the same year $\left(A T 0_{i}\right)$ and the soil water deficit at 1-year lag $\left(S D_{i-1}\right)$ :

$$
N P P_{i}=\alpha S D_{i-1}+\beta A T 0_{i}+\gamma
$$

where, $\alpha, \beta$ and $\gamma$ are parameters of the linear models, which can be estimated by the least square method.

\subsubsection{Sensitivity analysis of the NPP to precipitation and temperature}

The response degree of NPP to various changes of precipitation and temperature can be analyzed and calculated by using Eq.1 to 4 and Eq.10 in the SRYR and its sub-regions. With assumed plausible hypothetical climatic inputs, sensitivity of the NPP to precipitation and temperature can be analyzed as follows:

$$
\begin{aligned}
\Delta N P P_{\Delta P} & =\frac{N P P_{P+\Delta P, T}-N P P_{P, T}}{N P P_{P, T}} \times 100 \% \\
\Delta N P P_{\Delta T} & =\frac{N P P_{P, T+\Delta T}-N P P_{P, T}}{N P P_{P, T}} \times 100 \%
\end{aligned}
$$

where $N P P_{P, T}$ is the NPP under the combination of the present precipitation $(P)$ and temperature variable $(T) ; N P P_{P+\triangle P, T}$ and $N P P_{P, T+\triangle T}$ are the NPP under the certain precipitation variable $((P+\Delta P)(\%))$ and temperature variable $\left(T+\triangle T\left({ }^{\circ} \mathrm{C}\right)\right)$, respectively; $\triangle N P P_{\triangle P}\left(\triangle N P P_{\Delta T}\right)$ is the relative difference between $N P P_{P, T}$ and $N P P_{P+\triangle P, T}\left(\triangle N P P_{T+\Delta T}\right)$.

\section{Results}




\subsection{Distribution of NPP across the SRYR}

The average NPP of the SRYR during 2000 to 2014 are calculated and illustrated in Fig.2. The spatial distribution of multi-year average NPP shows that NPP is generally lower in the western SRYR and increases gradually toward the east, with an average value of $85.2 \mathrm{gC} / \mathrm{m}^{2}$ and a range from 1.5 to $531.7 \mathrm{gC} / \mathrm{m}^{2}$. The spatial correlation displayed in Fig. 3 shows that there may be an exponent relation between NPP and elevation. When the elevation is more than $5000 \mathrm{~m}$, NPP is less susceptible to changes in elevation. The resulting slope indicates that a $100 \mathrm{~m}$ increase in elevation corresponds to a decrease in NPP by $5.4 \mathrm{gC} / \mathrm{m}^{2}$. It is clear that NPP is more susceptible to the elevation increase in the region with elevation less than $5000 \mathrm{~m}$. The results show an increase of $10.5 \mathrm{gC} / \mathrm{m}^{2}$ for NPP with a $100 \mathrm{~m}$ increase of elevation.

[Figure 2]

Fig.2 The spatial distribution of multi-year average NPP

\section{[Figure 3]}

Fig.3 Average NPP in different elevation

The average annual NPP in different regions are illustrated in Fig.4. The regions where NPP ranges from 0 to $50 \mathrm{gC} / \mathrm{m}^{2}$, accounting for $31.6 \%$ of the total area, are mainly located in Tuotuo River Basin and Qumar River Basin. The regions with an average annual NPP of 50 to $100 \mathrm{gC} / \mathrm{m}^{2}$ are mainly distributed in Dam River Basin and Middle stream, accounting for 35.2\% of the total area. A high-value zone of average annual NPP can be observed in the Downstream, where NPP is more than $100 \mathrm{gC} / \mathrm{m}^{2}$, accounting for $33.2 \%$ of the total area.

\section{[Figure 4]}

Fig.4 Area percentages of regions with different grades in average annual NPP*

*Note: Sub-region I to V represent Tuotuo River Basin, Dam River Basin, Qumar River Basin, Middle stream and Downstream, respectively.

\subsection{Spatial-temporal variation of NPP across the SRYR}

The change in annual NPP in the SRYR (including all sub-regions) from 2000 to 2014 was calculated to determine the overall situation of NPP and the results are illustrated in Fig.5. It could be found that annual fluctuation in the total amount of NPP is obvious during the study period, with a range of 8.28-14.06 TgC. Between 2000 and 2004, the total amount of NPP remained relatively steady, and the value for the entire area was $10.11 \pm 0.32 \mathrm{TgC}$. However, an obvious decreasing trend can be observed from 2005 to 2008 . The lowest value of total NPP presented in 2008 , at only $8.28 \mathrm{TgC}$, which is $24.0 \%$ lower than the average annual total NPP. From 2008 to 2010 , total NPP in the SRYR had increased and reached the peak value of $14.06 \mathrm{TgC}$ in 2010 , with 29.0\% higher than the multi-year average. Although total NPP decreased during 2011 to 2014, it was still higher than the average annual NPP from 2000 to 2014 by $3.7 \%$. The total NPP had increased by $1.42 \mathrm{TgC}$ per year from 2000 to 2014 . But the trend was not significant according to Mann-Kendall test $(|Z|=1.533<1.96)$.

Fig.5 Changes in annual NPP in the SRYR*

\section{[Figure 5]}

*Note: Sub-region I to V represent Tuotuo River Basin, Dam River Basin, Qumar River Basin, Middle stream and Downstream, respectively. 
The change rate of NPP and trend significance level was analyzed by regression statistics and Mann-Kendall test cell by cell from the year 2000 to 2014 (Fig.6). The total NPP in most SRYR increased during the study period, with the change rate increasing from the west to the east.

234 Although the overall increase trend of NPP was not significant across SRYR, a significant regional NPP change trend was shown mainly in Tuotuo River Basin, Dam River Basin and upper reaches of Qumar River Basin. Areas with $|Z|>1.96$ (significant at $p>0.05$ ) accounted for about $56.5 \%$, 45.1\% and 26.2\% of Tuotuo River Basin, Dam River Basin and Qumar River Basin respectively. For the entire SRYR, area with significant increase trend accounted for $27.6 \%$ of the total area, while area with significant decrease trend accounted for only $0.12 \%$ of the total area.

Fig.6 Spatial trends of NPP in SRYR. The small inset map in Fig. 6 shows that the spatial pattern of trend significance levels marked by " $p$ ". The region filled in white is non-significant at $p>0.05$.

\subsection{Spatial-temporal variation in soil water deficit and accumulated temperature across the SRYR}

The average annual soil water deficit in the SRYR over the period 2000 to 2014 is $306.4 \mathrm{~mm}$, accounting for $71.0 \%$ of average annual precipitation. There was little inter-annual variability in soil water deficit from 2000 to 2004 , and the value for the entire area was $270.3 \pm 9.9 \mathrm{~mm}$. However, the inter-annual change in soil water deficit has been increasing since 2005. Annual soil water deficit during 2005 to 2014 was $320.3 \pm 97.4 \mathrm{~mm}$, which has increased by $14.3 \%$ compared with the average value during 2000 to 2004. From 2000 to 2014, the average annual soil water deficit in the SRYR showed an increasing trend with a rate of $5.98 \mathrm{~mm} / \mathrm{a}$ and this trend was statistical significant at $\alpha=0.1$ level $(|Z|=1.928>1.645)$ (Fig.7(a)). As indicated in the spatial trend distribution map (Fig.8(a)), the positive soil water deficit changes can be found in most parts of the SRYR (accounting for $99.6 \%$ of the area). The increase trend grew more severe in the easterly direction and a remarkable increase occurred in middle and lower reaches of the SRYR, with increase rate up to $6 \mathrm{~mm} / \mathrm{a}$.

The average annual accumulated temperature in the SRYR was $720.7^{\circ} \mathrm{C}$ from 2000 to 2014 . The inter-annual accumulated temperature variability displayed a similar trend to that of the soil water deficit. Before 2005, the average annual accumulated temperature in the SRYR was $684.5 \pm$ $23.8^{\circ} \mathrm{C}$ and showed a slight decrease trend. After 2005, the average annual accumulated temperature increased significantly, with the mean value of $739.5 \pm 103.3^{\circ} \mathrm{C}$. The average annual soil water deficit during 2005-2014 increased by $55.0^{\circ} \mathrm{C}$ compared with that from 2000 to 2004 . During the study period, the annual accumulated temperature generally exhibited an increasing trend, and it increased at a rate of $6.05^{\circ} \mathrm{C}$ per year on average. This increase trend was also statistical significant at $\alpha=0.1$ level $(|Z|=1.829>1.645)$ (Fig.7(b)). From the perspective of the pattern of change, accumulated temperature increased overall during the study period. The regions where the annual accumulated temperature increased by 2 to $4^{\circ} \mathrm{C} / \mathrm{a}, 4$ to $6^{\circ} \mathrm{C} / \mathrm{a}, 6$ to $8^{\circ} \mathrm{C} / \mathrm{a}$ and 8 to $26810^{\circ} \mathrm{C} / \mathrm{a}$ accounted for $12.7 \%, 37.8 \%, 35.4 \%$ and $14.1 \%$ of the entire SRYR respectively. The 
accounted for $19.7 \%$ of the total area and mainly distributed in the downstream of the $271 \quad$ SRYR(Fig.8(b)).

\subsection{Correlations between NPP and soil water deficit / accumulated temperature}

Scatter plots of NPP and hydrothermal conditions for five sub-regions and the whole SRYR were computed and fitted onto the regression curve, as shown in Fig. 9 and 10. It was apparent that the NPP of one specific year has obvious relationship with the accumulated temperature of the same year and the soil water deficit of the last year. Correlation coefficients revealed the highest correlation of NPP and soil water deficit at 1-year lag in the middle stream of SRYR $(R=0.813)$ and lowest correlation in Tuotuo River Basin $(R=0.545)$. The accumulated temperature had a higher correlation with NPP than soil water deficit at 1-year lag. Correlation coefficients between NPP and accumulated temperature were higher than 0.85 in all the sub-regions. It could be concluded that both water condition and temperature were dominating factors for the greenness trend of the vegetation, but temperature was more important than water condition.

\section{[Figure 9]}

Fig.9 Correlation between NPP and soil water deficit: (a) Tuotuo River Basin; (b) Dam River Basin;(c) Qumar River Basin;(d) Middle stream; (e) Downstream and (f) SRYR

\section{[Figure 10]}

Fig.10 Correlation between NPP and accumulated temperature: (a) Tuotuo River Basin; (b) Dam River Basin; (c) Qumar River Basin; (d) Middle stream; (e) Downstream and (f) SRYR

The correlation coefficient between NPP and soil water deficit / accumulated temperature for each cell is presented in Fig.11.The region where NPP is positively correlated with the soil water deficit and accumulated temperature accounts for $99.74 \%$ and $99.98 \%$ of the entire SRYR, in other words, the influence of hydrothermal conditions on NPP is positive in nearly all regions of the SRYR. The region showing a significant positive correlation between NPP and soil water deficit $\left(R_{N P P}\right.$ vs. $\left.S D \geqslant 0.5\right)$ accounts for $71.8 \%$ of the entire SRYR, mainly located in Middle and downstream of the SRYR. The region exhibiting a significant positive correlation with accumulated temperature $\left(R_{N P P}\right.$ vs. $\left.A T 0 \geqslant 0.5\right)$ accounts for $98.1 \%$ of the entire SRYR.

\section{[Figure 11]}

Fig.11 Correlation Coefficient between NPP and soil water deficit (a) / accumulated temperature (b)

\subsection{Sensitivity analysis of the NPP to hydrothermal conditions}

Based on the soil water deficit, accumulated temperature and NPP from 2000 to 2014, the response models of the NPP to soil water deficit / accumulated temperature in each sub-region and the entire SRYR, as well as $\alpha, \beta$ and $\gamma$ in the models and coefficients $(R)$ can be obtained by 
using a statistical software (Table 2). From Table 2 we can find that multiple correlation 311 coefficients between the NPP and soil water deficit $(S D)$ and accumulated temperature $(A T 0)$ in 312 Tuotuo River Basin, Dam River Basin, Qumar River Basin, Middle stream and the whole SRYR 313 are higher than 0.8 except the Downstream $(R=0.774)$. In addition, the significance level test 314 values (Sig F) of five sub-regions and the entire SRYR are less than 0.01 . This illustrates that the linear models have passed the significance test of $\alpha=0.01$ and can be used for sensitivity analysis.

Table 2 Response model of NPP to soil water deficit / accumulated temperature in five sub-regions and the entire SRYR

The sensitivity analysis derives eight different hydrographs for changes in precipitation (from $-20 \%$ to $+20 \%$ with a step of $5 \%$ ) and six different hydrographs for changes in temperature (from $-3^{\circ} \mathrm{C}$ to $+3^{\circ} \mathrm{C}$ with a step of $1.0^{\circ} \mathrm{C}$ ). The hydrographs were used to calculate the duration curves of soil water deficit and accumulated temperature. The relation between simulated changes in precipitation/temperature and soil water deficit/accumulated temperature are shown as Fig.12. The six lines show the effect of precipitation/temperature changes on average soil water deficit/accumulated temperature in five sub-basins and the entire SRYR. It can be seen that a $10 \%$ change in precipitation results in a $15.8 \%$ change in soil water deficit across the SRYR (dashed black line in Fig.12(a)). In the warmer climatic scenarios, land-surface evaporation as well as accumulated temperature increase, leading to less soil water deficit. The resulting slope indicates that a $1{ }^{\circ} \mathrm{C}$ increase in temperature corresponds to a decrease of $4.1 \%$ in soil water deficit and an increase of $143.4^{\circ} \mathrm{C}$ in accumulated temperature (dashed black lines in Fig.12(b) and Fig.12(c)).

Fig.12 Sensitivity on soil water deficit/ accumulated temperature due to precipitation and temperature change in the SRYR: (a) soil water deficit affected by precipitation change; (b) soil water deficit affected by temperature change; (c) accumulated temperature affected by temperature change

Using the response models in Table 1 and the soil water deficit / accumulated temperature simulated in hypothetical climatic scenarios, the change of NPP for different sub-regions and the entire SRYR can be calculated (Fig.13). It can be found that NPP in middle stream of the SRYR and Dam River Basin are more sensitive to precipitation. For a 10\% increase in precipitation, the

340 NPP in middle stream of the SRYR and Dam River Basin increase by 5.2\% (0.098 TgC) and 5.0\%

341 (0.139 $\mathrm{TgC})$ respectively. While NPP in Tuotuo River Basin is more sensitive to temperature 342 change. A $1{ }^{\circ} \mathrm{C}$ increase of temperature leads to a $29.7 \%(0.194 \mathrm{TgC})$ increase of NPP. For the 343 entire SRYR, the NPP increases by $4.7 \%(0.517 \mathrm{TgC})$ if the precipitation increased by $10 \%$, and a $34411^{\circ} \mathrm{C}$ increase of temperature results in a $20.6 \%(2.251 \mathrm{TgC})$ increase of NPP.

\section{[Figure 13]}

346 Fig.13 Sensitivity on NPP due to precipitation and temperature change in the SRYR

\section{5. Discussion}


The NPP series used for regression analysis in Section 4.4 and 4.5 was derived from MOD17A3 product, namely actual NPP (ANPP). Both climate change and human activities would affect the value of ANPP. However, according to the results in Section 4.4 and 4.5, the actual NPP was highly correlated with climatic variables. We can conclude that climate change is dominant factor impacting vegetation growth in the SRYR while the effect coming from human activities is much less. In order to demonstrate these results, another two other types of NPP, namely potential NPP (PNPP) and human activity-related NPP or NPP loss (HNPP) have been introduced. With the Miami Model (Lieth et al.,1972), a simple conceptual model that links NPP to annual mean temperature and annual precipitation, the PNPP can be estimated. Then, the HNPP can be obtained by PNPP minus ANPP (Zhou et al.,2015; Teng et al., 2020). According to the identification method provided by Zhou et al. (2015), the spatial distribution of different driving forces of changes in NPP from 2001 to 2014 in the SRYR can be obtained (Fig.14). It can be concluded that climate variations over time led to ANPP increasing in most of the SRYR. Climate variations independently accounted for ANPP increases in $95.7 \%$ of the SRYR (blue area in Fig. 14). The human activities are responsible for the decrease of ANPP. About $2.3 \%$ of the SRYR show decreasing ANPP trends owning to human activities (red area in Fig.14). Besides, about 1.9\% of the SRYR shows increasing ANPP trends owing to combined impact of climate change and human activities (yellow area in Fig.14). This kind of area is mainly located in the downstream of the SRYR. The grassland was restored and vegetation NPP increased because of some effective conservation programs, such as Grain for Green Program, Grazing Withdrawal Program.

\section{[Figure 14]}

Fig. 14. Spatial distribution of different driving forces of changes in NPP from 2000 to 2014 in the SRYR

\subsection{Warming, wetting and greening SRYR: is that a good thing?}

Increases in accumulated temperature, soil water deficit and NPP over the SRYR during 2000 to 2014 were identified in this study, indicating a warming, wetting and greening SRYR in recent decade. In fact, these changes were not limited to the SRYR but across the Tibetan Plateau (Yang et al., 2011; Haynes et al., 2014; Zhang, et al., 2017). And these trends were projected to be continued under future climate change (Gao et al. 2016; Lamsal et al., 2017; Yuan et al., 2019a). In addition, many previous studies found that the temperature was the dominant climate factor impacting vegetation growth in the alpine region (Li et al., 2013; Yuan et al., 2019b). The increase of temperature in the alpine region leaded to advanced start of growth season and delayed end of growth season. And the length of growing season prolonged as well. Accordingly, NPP of alpine vegetation also substantially increased (Ding, et al., 2013; Wang et al,2017).

The greening SRYR means carbon sink of vegetation has been increasing. It will help to mitigate and adapt to the climate change. However, substantial organic carbon has been stored in the frozen soil of the SRYR. As the temperature increasing, the freezing duration would be 
negative one mentioned above may make the fate of carbon balance more complicated in the future. Besides, the alpine region is vulnerable to climate changes because the biodiversity can be changed drastically in altitudinal gradients (Beniston, 2003; Kammer et al., 2007). The tree line, one of the most conspicuous vegetation boundaries (Körner, 1998; Holtmeier, 2009), was expected shift to higher latitudes in warmer climate condition not only in the SRYR or Tibetan Plateau, but also in other high mountain areas (Leonelli et al., 2011; Liang et al.,2012; Gaire et al., 2014; Liang et al.,2016). As a consequence, the suitable area for alpine shrub and meadow would be reduced, leading to an increase of population density and competition. The risk of extinction for endemic species in high mountain areas would increase along with it.

\section{Conclusion}

In this study, the effects of hydrothermal conditions on the Net Primary Productivity (NPP) in the Source Region of Yangtze River (SRYR) were analyzed. According to the remote sensing data and meteorological data, the spatial-temporal variations of NPP, water conditions (soil water deficit) and thermal conditions ( $\geqslant 0{ }^{\circ} \mathrm{C}$ accumulated temperature) were identified. Then correlations between NPP and hydrothermal conditions, and sensitivity of NPP to climate change were investigated. The primary conclusions are as follows:

(1) The NPP of SRYR is characterized by significant spatial differences, higher values in the east and lower values in the west, showing an average value of $85.2 \mathrm{gC} / \mathrm{m}^{2}$ from 2000 to 2014 over the region as a whole. Elevation is an important role in the spatial differentiation of NPP with a dividing line of approximately $5000 \mathrm{~m}$. Below this line, the NPP is susceptible to elevation increase, whereas above the line, the NPP is less susceptible to changes in elevation.

(2) The annual total NPP across the NPP ranges from 8.28 to $14.06 \mathrm{TgC}$ and shows an increase trend with some fluctuation during 2001 to 2014. In general, the areas where the NPP having significant increase and decrease trends account for $27.6 \%$ and $0.12 \%$ of the total area, respectively. The NPP changes fastest in the Downstream region, followed by middle stream region and Dam River Basin.

(3) The annual soil water deficit ranges from 222.9 to $417.7 \mathrm{~mm}$ with an average value of $306.4 \mathrm{~mm}$, and the annual accumulated temperature ranges from 636.3 to $842.8^{\circ} \mathrm{C}$ with an average value of $720.7^{\circ} \mathrm{C}$ in the SRYR. Both of them show an overall increasing trend with some fluctuation from 2000 to 2014.

(4) On an inter-annual level, the NPP of one specific year $\left(N P P_{i}\right)$ has obvious relationship with the accumulated temperature of the same year $\left(A T 0_{i}\right)$ and the soil water deficit of the last year $\left(S D_{i-1}\right)$. The region where NPP is positively and significantly correlated with the soil water deficit and accumulated temperature accounts for $71.8 \%$ and $98.1 \%$ of the entire SRYR. The NPP is much more correlated with accumulated temperature than with soil water deficit. The temperature is the dominant climate factor impacting vegetation growth in the SRYR.

(5) The NPP in SRYR is more sensitive to changes in temperature than changes in precipitation. It is shown that the NPP increases $0.194 \mathrm{TgC}$ (nearly $30 \%$ ) with every $1-^{\circ} \mathrm{C}$ increase in annual mean temperature. While a $10 \%$ increase in annual precipitation corresponds to an increase in NPP by $0.517 \mathrm{TgC}$ (nearly $5 \%$ ). 


\section{Ethics approval and consent to participate}

$430 \quad$ Not applicable.

\section{Consent for publication}

$432 \quad$ All of the authors have reviewed and approved the manuscript for publication.

\section{Availability of supporting data}

434 Data from this study is available upon request.

\section{Competing interests}

436 The authors declare that they have no competing interests.

\section{$437 \quad$ Funding}

438 This research was funded by [National Natural Science Foundation of China] grant number 439 [41890821,51709008, 51639005]; [National Key Research and Development Project] grant 440 number [2017YFC1502404]; [National Public Research Institutes for Basic R\&D Operating 441 Expenses Special Project] grant number [CKSF2019292/SH+SZ, CKSF2017061/SZ].

\section{Authors' contributions}

ZY, YW, and JX conceived the study and provided overall guidance. ZY prepared the first draft and finalized the manuscript based on comments from all other authors. ZY, JY and SC had major roles in formulating the analysis. All other authors contributed to the analysis and reviewed the manuscript. The authors read and approved the final manuscript.

\section{Acknowledgements}

We acknowledge the contributions of the staff of Changjiang River Scientific Research Institute, Hubei University.

\section{Authors' information}

451 Changjiang River Scientific Research Institute, Changjiang Water Resources Commission of the

452 Ministry of Water Resources of China, Wuhan, China.

453 Zhe Yuan yuanzhe 0116@126.com

454 Yongqiang Wang wangyq@mail.crsri.cn

455 Jijun Xu $\underline{x u j i j 07 @ 163 . c o m}$

$456 \quad$ Shu Chen cs1152692409@163.com 
Faculty of Resources and Environmental Science, Hubei University, Wuhan, China.

Jun Yin yinjun19880209@126.com

\section{Reference}

Ahlström, A., Miller, P.A., Smith, B., 2012. Too early to infer a global NPP decline since 2000. Geophys. Res. Lett. 39, L15403.

Bajgiran, P. R., Darvishsefat, A. A., Khalili, A., Makhdoum, M. F., 2008. Using AVHRR-based vegetation indices for drought monitoring in the Northwest of Iran. J. Arid Environ. 72(6), 1086-1096.

Beerling, D.J., Osborne, C.P., 2006. The origin of the savanna biome. Global Change Biol.12, 2023-2031.

Beniston, M., 2003. Climatic change in mountain regions: a review of possible impacts. In: Climate Variability and Change in High Elevation Regions: Past, Present and Future. Springer.

Byrne, K. M., Lauenroth, W. K., Adler, P. B., 2013. Contrasting Effects of Precipitation Manipulations on Production in Two Sites within the Central Grassland Region, USA. Ecosystems, 6(6),1039-1051.

Chen, J. 2013. Water cycle mechanism in the source region of Yangtze River. J. Yangtze River Sci. Res. Inst. 30(4):1-5. (in Chinese)..

Ding, M., Zhang, Y., Sun, X., Liu, L., Wang, Z., Bai, W., 2013. Spatiotemporal variation in alpine grassland phenology in the Qinghai-Tibetan Plateau from 1999 to 2009. Chinese Sci. Bull. 58(3), 396-405.

Du, Y., Berndtsson, R., An, D., Zhang, L., Hao, Z., Yuan, F., 2017. Hydrologic Response of Climate Change in the Source Region of the Yangtze River, Based on Water Balance Analysis. Water, 9, 115.

Frank, D., Reichstein, M., Bahn, M., Thonicke, K., Frank, D., Mahecha, M.D., Smith, P.,van der Velde, M., Vicca, S., Babst, F., Beer, C., Buchmann, N., Canadell, J.G., Ciais, P., Cramer, W., Ibrom, A., Miglietta, F., Poulter, B., Rammig, A., Seneviratne, S.I., Walz, A., Wattenbach, M., Zavala, M.A., Zscheischler, J., 2015. Effects of climate extremes on the terrestrial carbon cycle: concepts, processes and potential future impacts. Global Change Biol. 21, 2861-2880.

Gaire, N. P., Koirala, M., Bhuju, D. R., Borgaonkar, H. P., 2014. Treeline dynamics with climate change at the central Nepal Himalaya. Clim. Past. 10(4), 1277-1290.

Gang. C., Zhou, W., Wang, Z., Chen, Y., Li, J., Chen, J., Qi, J., Odeh, I., Groisman, P., 2015. Comparative assessment of grassland NPP dynamics in response to climate change in China, North America, Europe and Australia from 1981 to 2010. J. Agron. Crop. Sci. 201(1), 57-68.

Gao, Q., Guo, Y., Xu, H., Ganjurjav, H., Li, Y., Wan, Y., Qin, X., Ma, X., Liu, S., 2016. Climate change and its impacts on vegetation distribution and net primary productivity of the alpine ecosystem in the Qinghai-Tibetan Plateau. Sci. Total Environ. 554, 34-41.

Gao, Q., Li, Y., Wan, Y., Qin, X., Jiangcun, W., Liu, Y., 2009. Dynamics of alpine grassland NPP and its response to climate change in Northern Tibet. Clim. Chang. 97(3-4), 515-528. 
Goldewijk, K.K., Leemans, R. Systems models of terrestrial carbon cycling. Carbon sequestration in the biosphere. Springer, Berlin, Heidelberg.1995, 129-151.

Haberl, H., Fischer-Kowalski, M., 2007. Quantifying and mapping the human appropriation of net primary production in earth's terrestrial ecosystems. P. Natl. Acad. Sci. USA. 104(31), 12942-12947.

Haynes, M.A., Kung, K.-J.S., Brandt, J.S., Yongping, Y., Waller, D.M., 2014. Accelerated climate change and its potential impact on Yak herding livelihoods in the eastern Tibetan plateau. Clim. Chang. 123 (2), 147-160.

Holtmeier, F. K., 2009. Mountain timberlines: Ecology, patchiness and dynamics, Springer, Havixbeck, Germany.

Jiang, L., Chen, H., Zhu, Q., Yang, Y., Li, M., Peng, C., Zhu, D., He, Y., 2019. Assessment of frozen ground organic carbon pool on the Qinghai-Tibet Plateau. J. Soil Sediment. 19(1), 128-139.

Jin, Y., Li, J., Liu, C., Liu, Y., Zhang, Y., Song, Q., Sha, L., Chen, A., Yang, D., Li, P., 2018. Response of net primary productivity to precipitation exclusion in a savanna ecosystem. Forest Ecol. Manag. 429, 69-76.

Justice, C. O., Vermote, E., Townshend, J. R. , Defries, R., Roy, D. P., Hall, D. K., Salomonson, V. V., Privette, J. L., Riggs, G., Strahler, A., 1998. The Moderate Resolution Imaging Spectroradiometer (MODIS): land remote sensing for global change research. IEEE Trans. Geosci. Remote Sens. 36 (4), 1228-1249.

Kammer, P.M., Schöb, C., Choler, P., 2007. Increasing species richness on mountain summits: Upward migration due to anthropogenic climate change or re-colonisation? J. Veg. Sci. 18 (2), 301-306.

Kendall, M. G., 1948. Rank Correlation Methods. London: Charles Griffin.

Körner, C., 1998.Re-assessment of high elevation tree line positions and their explanation, Oecologia, 115, 445-459.

Lamsal, P., Kumar, L., Shabani, F., Atreya, K., 2017. The greening of the Himalayas and Tibetan Plateau under climate change. Global Planet. Change. 159, 77-92.

Leith, H., Whittaker, R., 1975. Primary production of the biosphere. Ecol. Stud. 14, 339.

Leonelli, G., Pelfini, M., di Cella, U. M., Garavaglia, V., 2011. Climate warming and the recent treeline shift in the European Alps: the role of geomorphological factors in high-altitude sites. Ambio, 40(3), 264-273.

Li, J., Wang, Z., Lai, C., Wu, X., Zeng, Z., Chen, X., Lian, Y., 2018. Response of net primary production to land use and land cover change in mainland China since the late 1980s. Sci. Total Environ. 639, 237-247.

Li, W., Li, C., Liu, X., He, D., Bao, A., Yi, Q., Wang, B., Liu, T., 2018. Analysis of spatial-temporal variation in NPP based on hydrothermal conditions in the Lancang-Mekong River Basin from 2000 to 2014. Environ. Monit. Assess. 190(6), 321.

Liang, E., Lu, X., Ren, P., Li, X., Zhu, L., Eckstein, D., 2012. Annual increments of juniper dwarf shrubs above the tree line on the central Tibetan Plateau: a useful climatic proxy. Ann. Bot. 109(4), 721-728.

Liang, E., Wang, Y., Piao, S., Lu, X., Camarero, J. J., Zhu, H., Zhu, L., Ellison, A.M., Ciais, P., 
Peñuelas, J., 2016. Species interactions slow warming-induced upward shifts of treelines on the Tibetan Plateau. P. Natl. Acad. Sci. USA. 113(16), 4380-4385.

Lieth, H., 1972. Modelling the primary productivity of the world. Nature and Resources, 8(2), 11-20.

Mann, H. B.,1945. Nonparametric tests against trend. Econometrica, 13(3), 245-259.

Mohamed, M. A. A., Babiker, I. S., Chen, Z. M., Ikeda, K., Ohta, K., Kato, K., 2004. The role of climate variability in the inter-annual variation of terrestrial net primary production (NPP). Sci. Total Environ. 332, 123-137.

Motew, M. M., Kucharik, C. J., 2013. Climate-induced changes in biome distribution, NPP, and hydrology in the Upper Midwest US: A case study for potential vegetation. J. Geophys. Res-Biogeo. 118(1), 248-264.

Nemani, R. R., Keeling, C. D., Hashimoto, H., Jolly, W. M., Piper, S. C., Tucker, C. J., Myneni, R. B., Running, S. W., 2003. Climate-driven increases in global terrestrial net primary production from 1982 to 1999. Science. 300(5625),1560-1563.

Nezlin, N. P., Kostianoy, A. G., Li, B. L., 2005. Inter-annual variability and interaction of remote-sensed vegetation index and atmospheric precipitation in the Aral Sea region. J. Arid Environ. 62(4), 677-700.

Peng, F., Xue, X., You, Q., Zhou, X., Wang, T., 2015. Warming effects on carbon release in a permafrost area of Qinghai-Tibet Plateau. Environ. Earth Sci. 73(1), 57-66.

Piao, S., Cui, M., Chen, A., Wang, X., Ciais, P., Liu, J., Tang, Y., 2011. Altitude and temperature dependence of change in the spring vegetation green-up date from 1982 to 2006 in the Qinghai-Xizang Plateau. Agr. Forest Meteorol. 151(12), 1599-1608.

Takahashi, K. L., 1979. Empirical Equation of Estimating Evaporation Using Monthly Average Temperature and Precipitation. Weather. 26(12), 29-32.

Teng, M., Zeng, L., Hu, W., Wang, P., Yan, Z., He, W., Zhang, Y., Huang, Z., Xiao, W., 2020. The impacts of climate changes and human activities on net primary productivity vary across an ecotone zone in Northwest China. Sci. Total Environ. 714, 136691.

Tian, Z., Zhang, D., He, X., 2019. Spatio-temporal variations in vegetation net primary productivity and their driving factors in Yellow River Basin from 2000 to 2015. Research of Soil and Water Conservation, 26(2), 255-262. (in Chinese)

Tripathi, P., Behera, M. D., Behera, S. K., Sahu, N., 2019. Investigating the contribution of climate variables to estimates of net primary productivity in a tropical deciduous forest in India. Environ. Monit. Assess. 191(3), 798.

Tum, M., Zeidler, J. N., Günther, K. P., Esch, T., 2016. Global NPP and straw bioenergy trends for 2000-2014. Biomass Bioenerg. 90, 230-236.

Wang, Q., Zeng, J., Leng, S., Fan, B., Tang, J., Jiang, C., Huang, Y., Zhang, Q., Qu, Y., Wang, W., Shui, W., 2018. Front. Earth Sci. 12(4): 818-833.

Wang, S., Zhang, B., Yang, Q., Chen, G., Yang, B., Lu, L., Shen, M., Peng, Y., 2017. Responses of net primary productivity to phenological dynamics in the Tibetan Plateau, China. Agr. Forest Meteorol. 232, 235-246.

Yan, M., Liu, X., Zhang, W., Li, X., Liu, S., 2011. Spatio-temporal changes of $\geq 10^{\circ} \mathrm{C}$ accumulated temperature in northeastern China since 1961. Chinese Geogr. Sci. 21(1): 17-26. 
Yang, K., Ye, B., Zhou, D., Wu, B., Foken, T., Qin, J., Zhou, Z., 2011. Response of hydrological cycle to recent climate changes in the Tibetan Plateau. Clim. Chang. 109(3-4), 517-534.

Yuan, Z., Xu, J., Wang, Y., 2019a. Historical and future changes of blue water and green water resources in the Yangtze River source region, China. Theor. Appl. Climatol.138, 1035-1047.

Yuan, Z., Yu, Z., Feng, Z., Xu, J., Yin, J., Yan, B., Lei, H., 2019b. Spatiotemporal variations of NDVI in terrestrial ecosystem in Yangtze River Basin and response to hydrothermal condition. Journal of Yangtze River Scientific Research Institute. 36(11): 7-15. (in Chinese)

Zhang, W., Zhou T, Zhang L., 2017. Wetting and greening Tibetan Plateau in early summer in recent decades. J. Geophys. Res.-Atmos. 122(11), 5808-5822.

Zhang, X., Sun, Y., Zheng, D., Mao, W., 2011. Responses of temperature zone boundaries in the arid region of China to climatic warming. Acta Geographica Sinica, 66(9), 1166-1178. (in Chinese).

Zhang, Y., 2010. Study on water supply-demand equilibrium and ecological adaptability of dryland farming systems in hot and summer drought areas. M. S. thesis. Southwest University, Chongqing, China.

Zheng, Z., Zhu, W., Zhang, Y., 2020. Seasonally and spatially varied controls of climatic factors on net primary productivity in alpine grasslands on the Tibetan Plateau. Glob. Ecol. Conserv. 21, e00814.

Zhou, G., Zhang, S., 1996. Study on NPP of natural vegetation in China under global climate change. Acta Ecologica Sinica. 20(1), 11-19.

Zhou, W., Gang, C., Zhou, F., Li, J., Dong, X., Zhao, C, 2015. Quantitative assessment of the individual contribution of climate and human factors to desertification in northwest China using net primary productivity as an indicator. Ecol. Indic. 48, 560-569.

\section{Table}

Table 1 Runoff coefficients for different slopes

\begin{tabular}{ccccccc}
\hline Slope & 0 to $5^{\circ}$ & 0 to $10^{\circ}$ & 10 to $15^{\circ}$ & 15 to $20^{\circ}$ & 20 to $25^{\circ}$ & $>25^{\circ}$ \\
\hline Runoff coefficient $(\alpha)$ & 0 & 0.04 & 0.12 & 0.2 & 0.27 & 0.35 \\
\hline
\end{tabular}

Table 2 Response model of NPP to soil water deficit / accumulated temperature in five sub-regions and the entire SRYR

\begin{tabular}{cccc}
\hline Region & Response models & $R$ & Significance F \\
\hline Tuotuo River Basin & $N P P_{i}=0.0003 \times S D_{i-1}+0.0015 \times A T 0_{i}-0.3379$ & 0.817 & $1.22 \mathrm{E}-05$ \\
Dam River Basin & $N P P_{i}=0.0018 \times S D_{i-1}+0.0034 \times A T 0_{i}-0.9506$ & 0.827 & $6.53 \mathrm{E}-05$ \\
Qumar River Basin & $N P P_{i}=0.0008 \times S D_{i-1}+0.0016 \times A T 0_{i}-0.3097$ & 0.847 & $3.27 \mathrm{E}-05$ \\
Middle stream & $N P P_{i}=0.0031 \times S D_{i-1}+0.0035 \times A T 0_{i}-0.8395$ & 0.822 & $3.05 \mathrm{E}-05$ \\
Downstream & $N P P_{i}=0.0025 \times S D_{i-1}+0.0072 \times A T 0_{i}-2.0869$ & 0.774 & $2.79 \mathrm{E}-04$ \\
SRYR & $N P P_{i}=0.0108 \times S D_{i-1}+0.0166 \times A T 0_{i}-4.3313$ & 0.849 & $1.22 \mathrm{E}-05$ \\
\hline
\end{tabular}

\section{Figure}




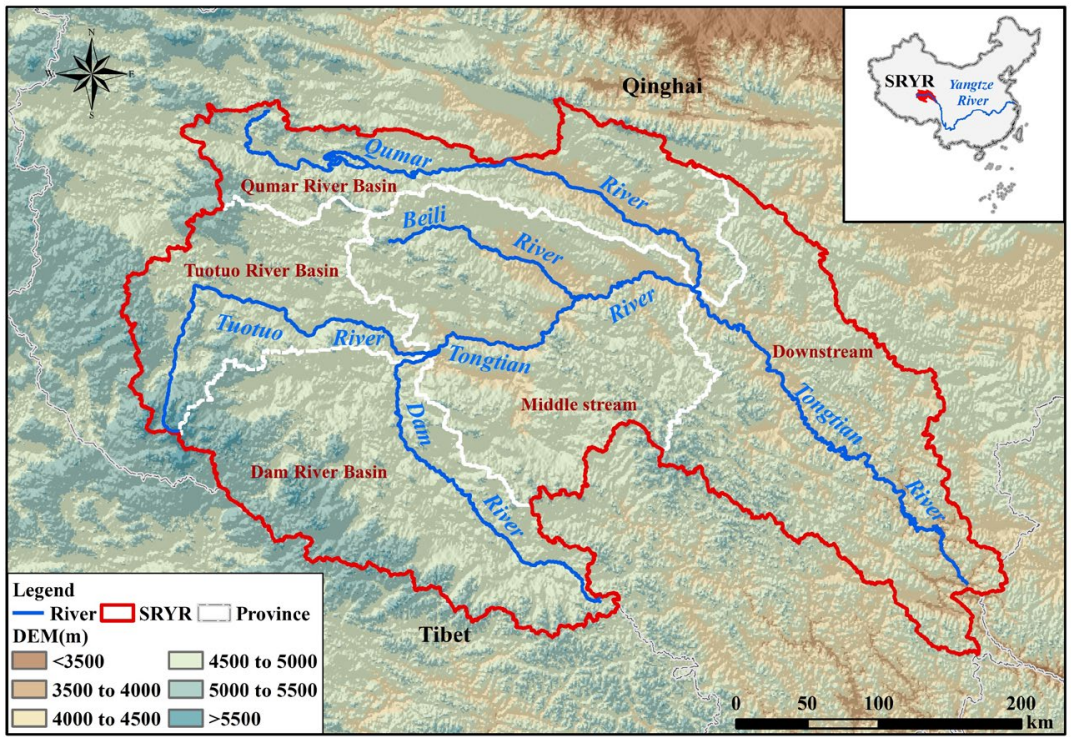

Fig.1 The location of Source Region of Yangtze River (SRYR)

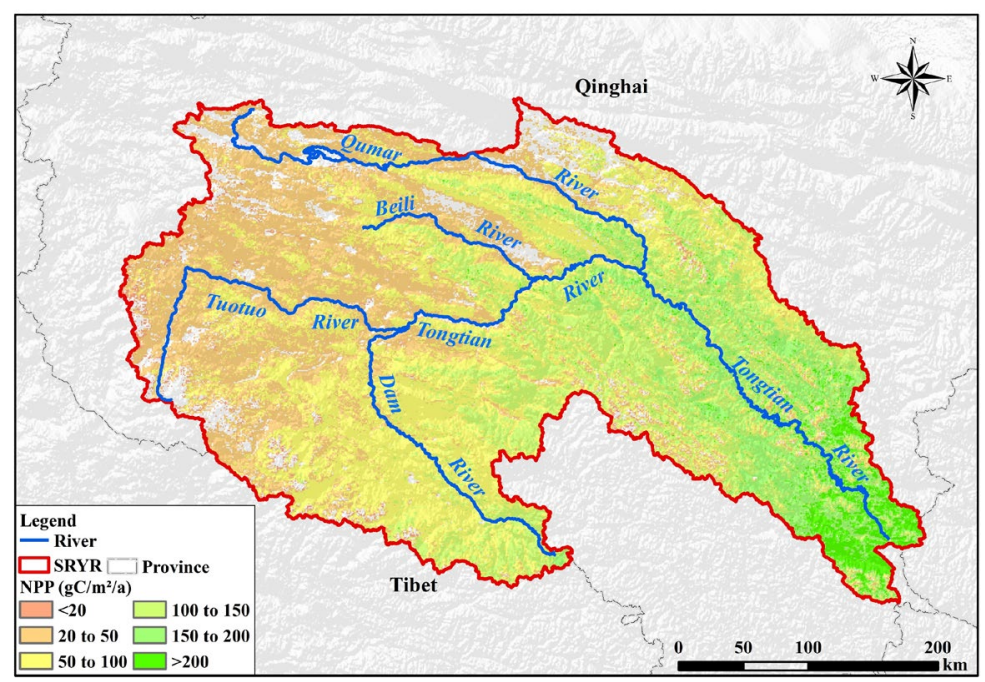

Fig.2 The spatial distribution of multi-year average NPP

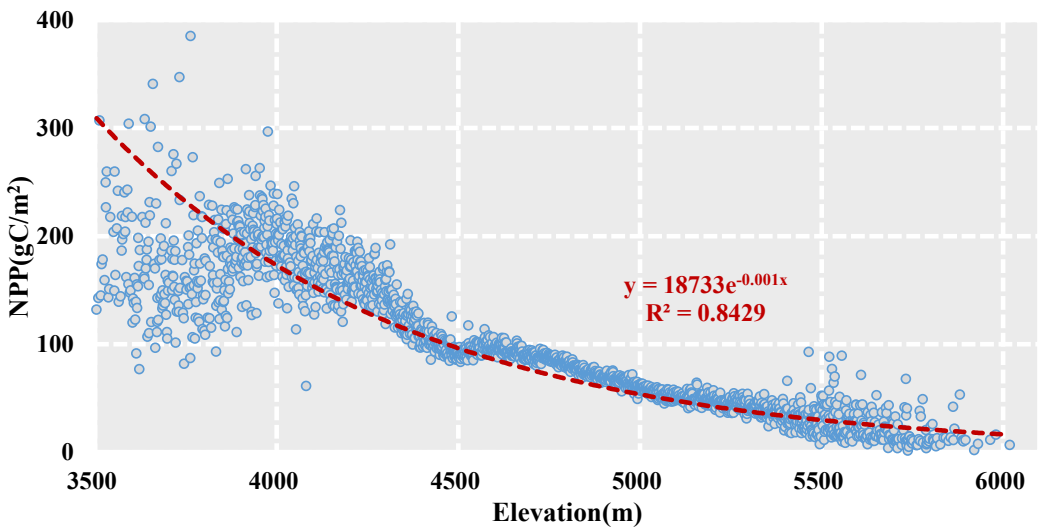




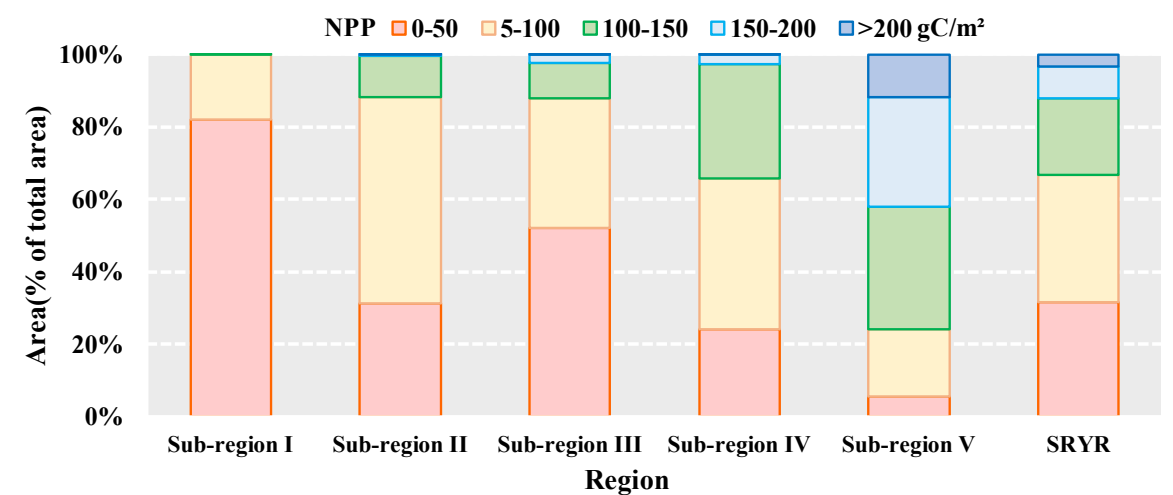

Fig.4 Area percentages of regions with different grades in average annual NPP

619

*Note: Sub-region I to V represent Tuotuo River Basin, Dam River Basin, Qumar River Basin, Middle stream and Downstream, respectively.

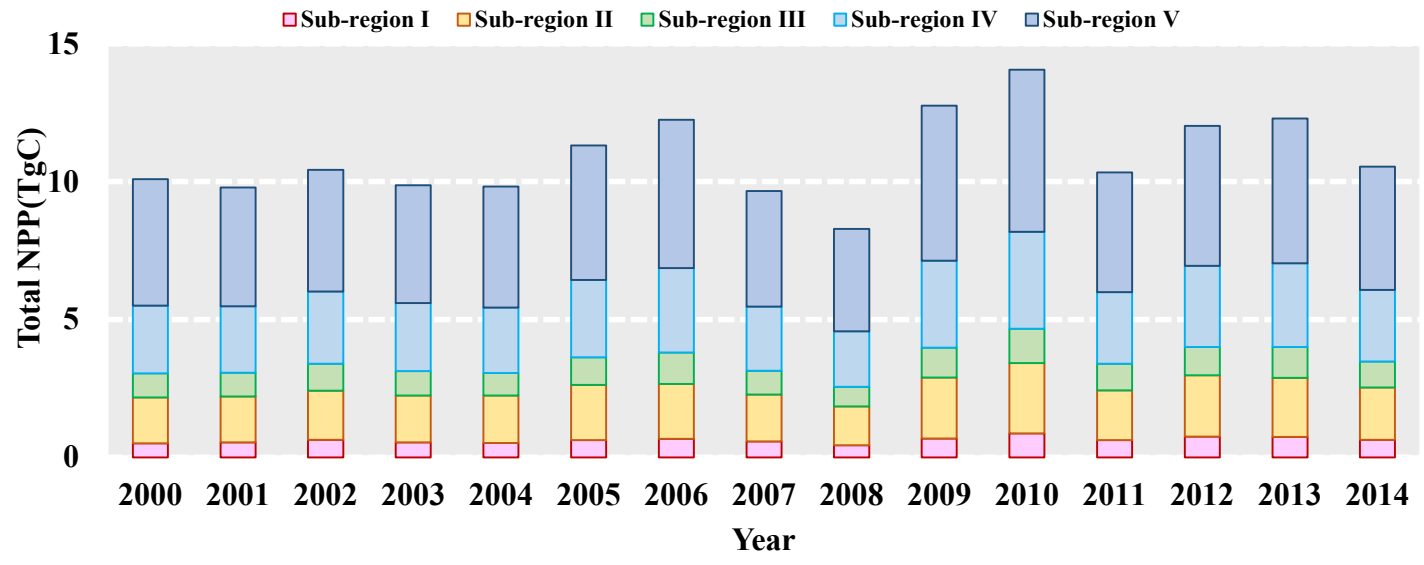

Fig.5 Changes in annual NPP in the SRYR*

*Note: Sub-region I to V represent Tuotuo River Basin, Dam River Basin, Qumar River Basin, Middle stream and Downstream, respectively.

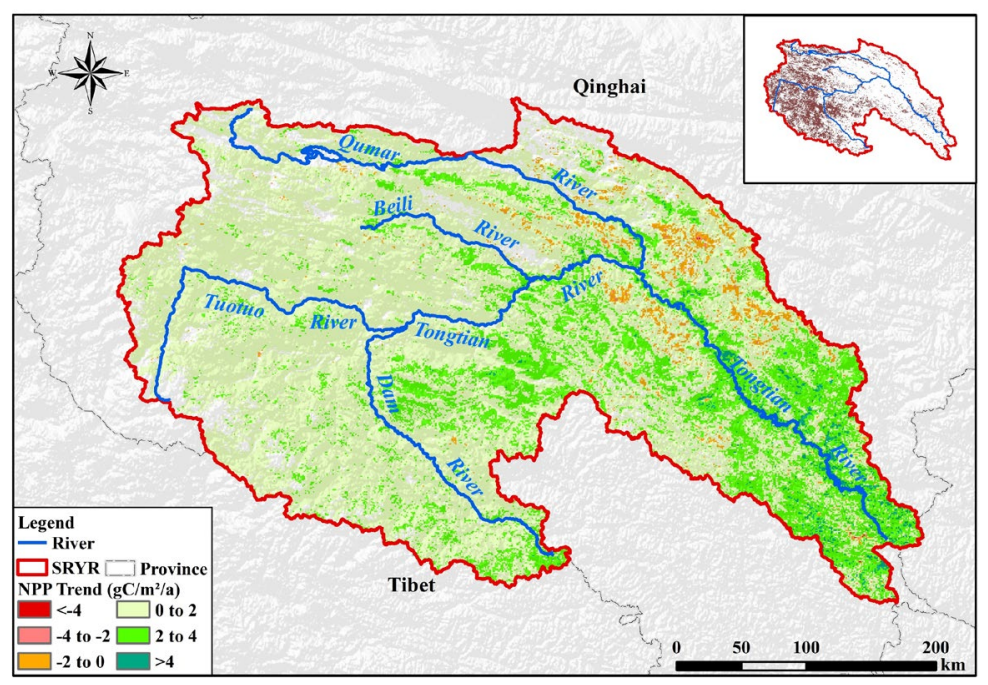

626 Fig.6 Spatial trends of NPP in SRYR. The small inset map in Fig. 6 shows that the spatial pattern of trend significance levels marked by " $p$ ". The region filled in white is non-significant at $p>0.05$. 

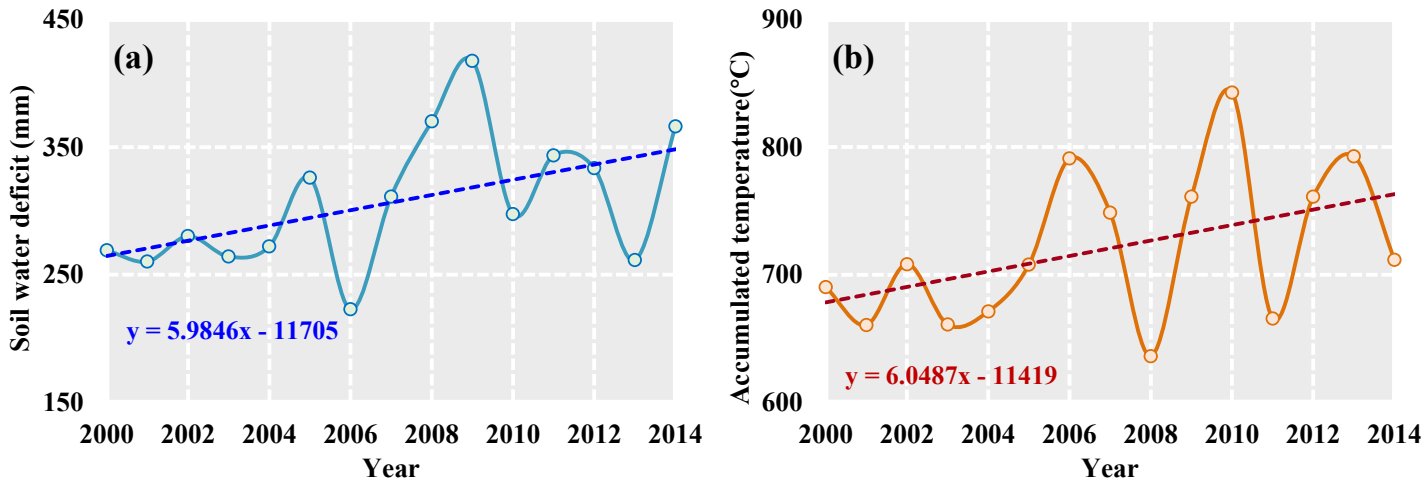

Fig.7 Changes in annual effective precipitation (a) and accumulated temperature (b) in the SRYR
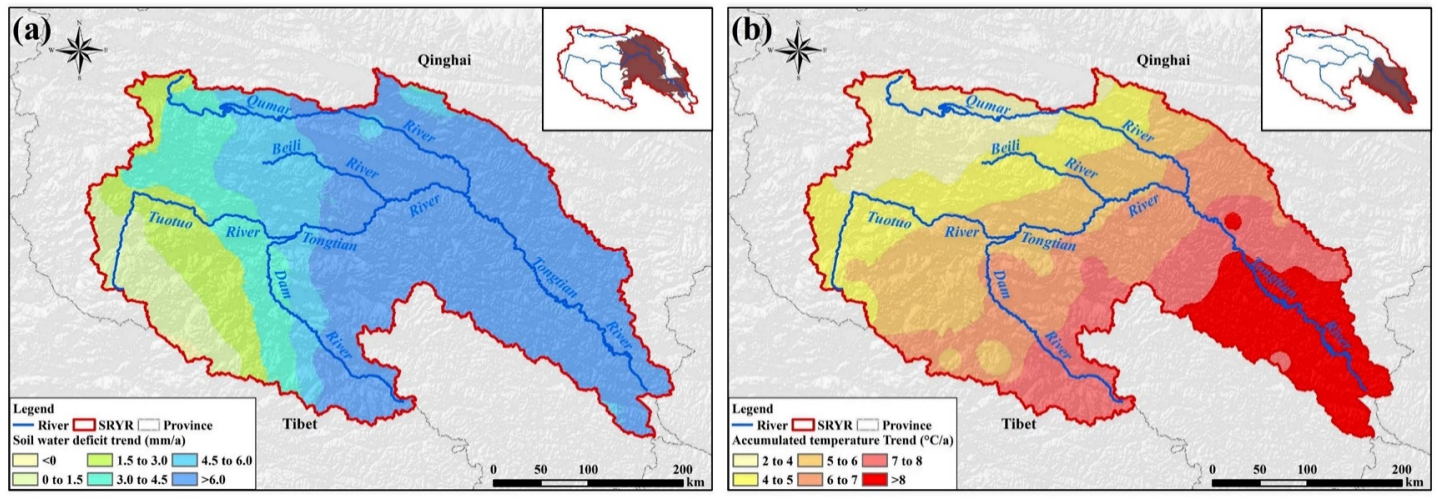

Fig.8 Spatial trends of soil water deficit and accumulated temperature in SRYR. The small inset map in Fig.

8 shows that the spatial pattern of trend significance levels marked by " $p$ ". The region filled in white is
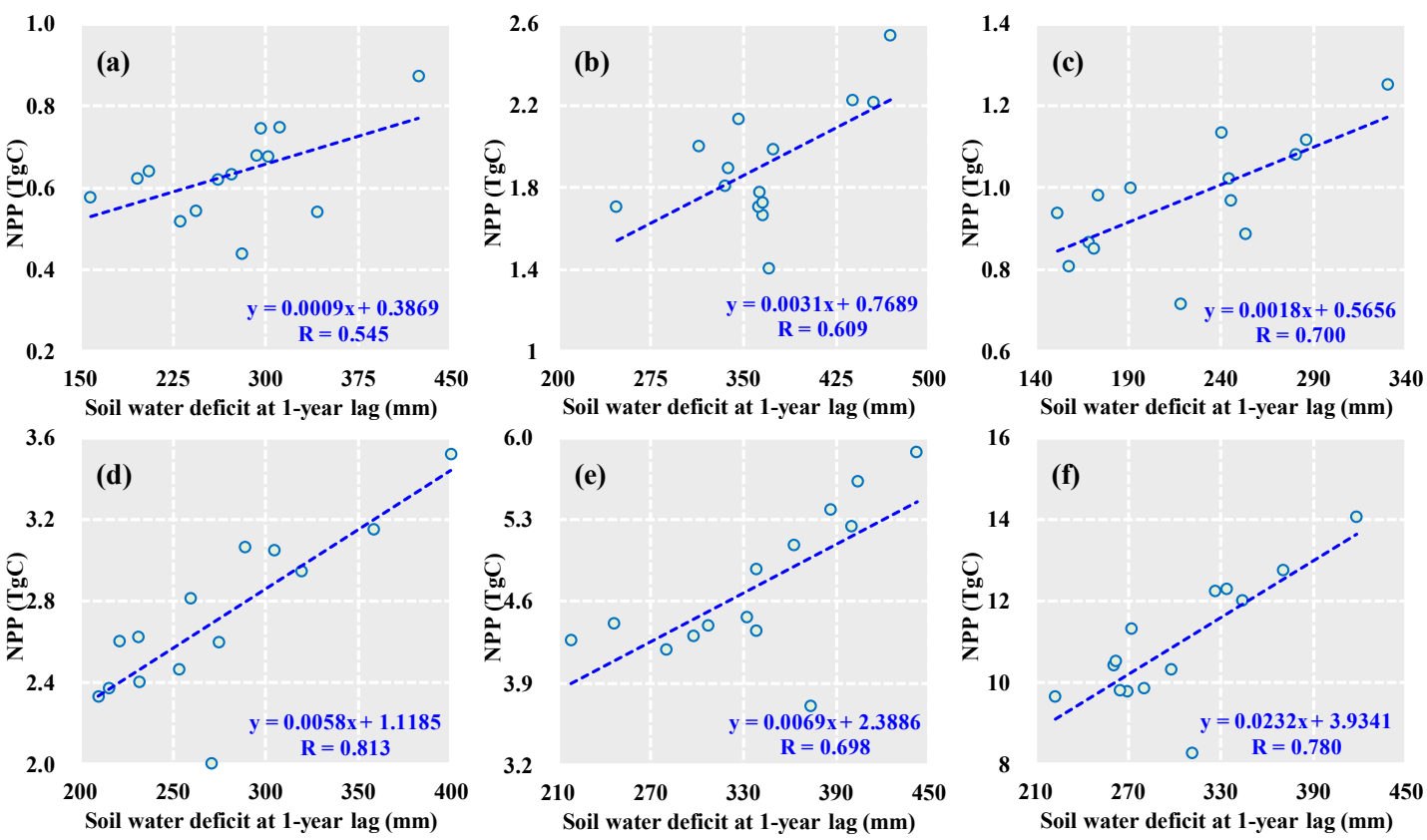

Fig.9 Correlation between NPP and soil water deficit: (a) Tuotuo River Basin; (b) Dam River Basin;(c) Qumar River Basin;(d) Middle stream; (e) Downstream and (f) SRYR 

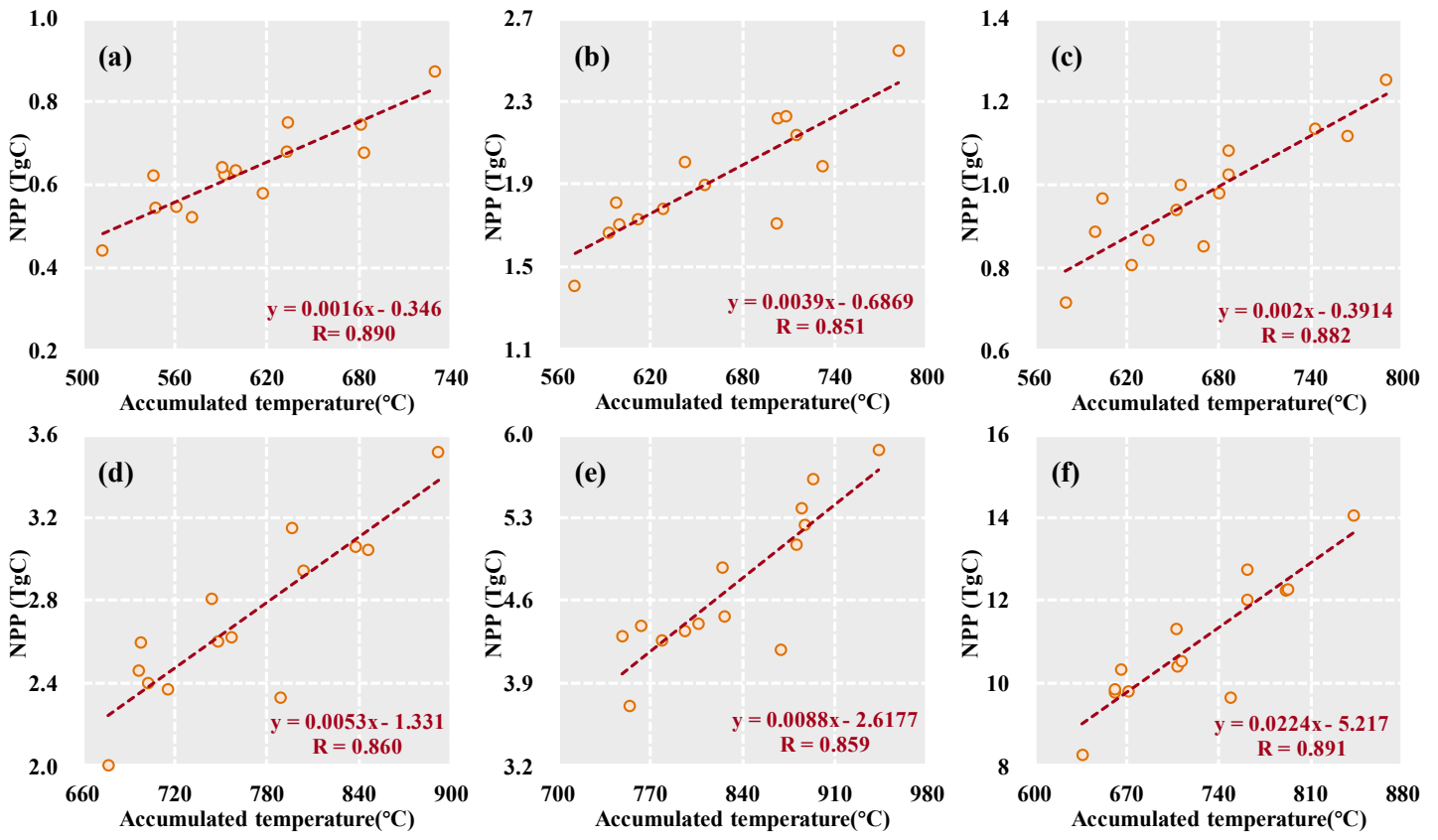

Fig.10 Correlation between NPP and accumulated temperature: (a) Tuotuo River Basin; (b) Dam River Basin; (c) Qumar River Basin; (d) Middle stream; (e) Downstream and (f) SRYR
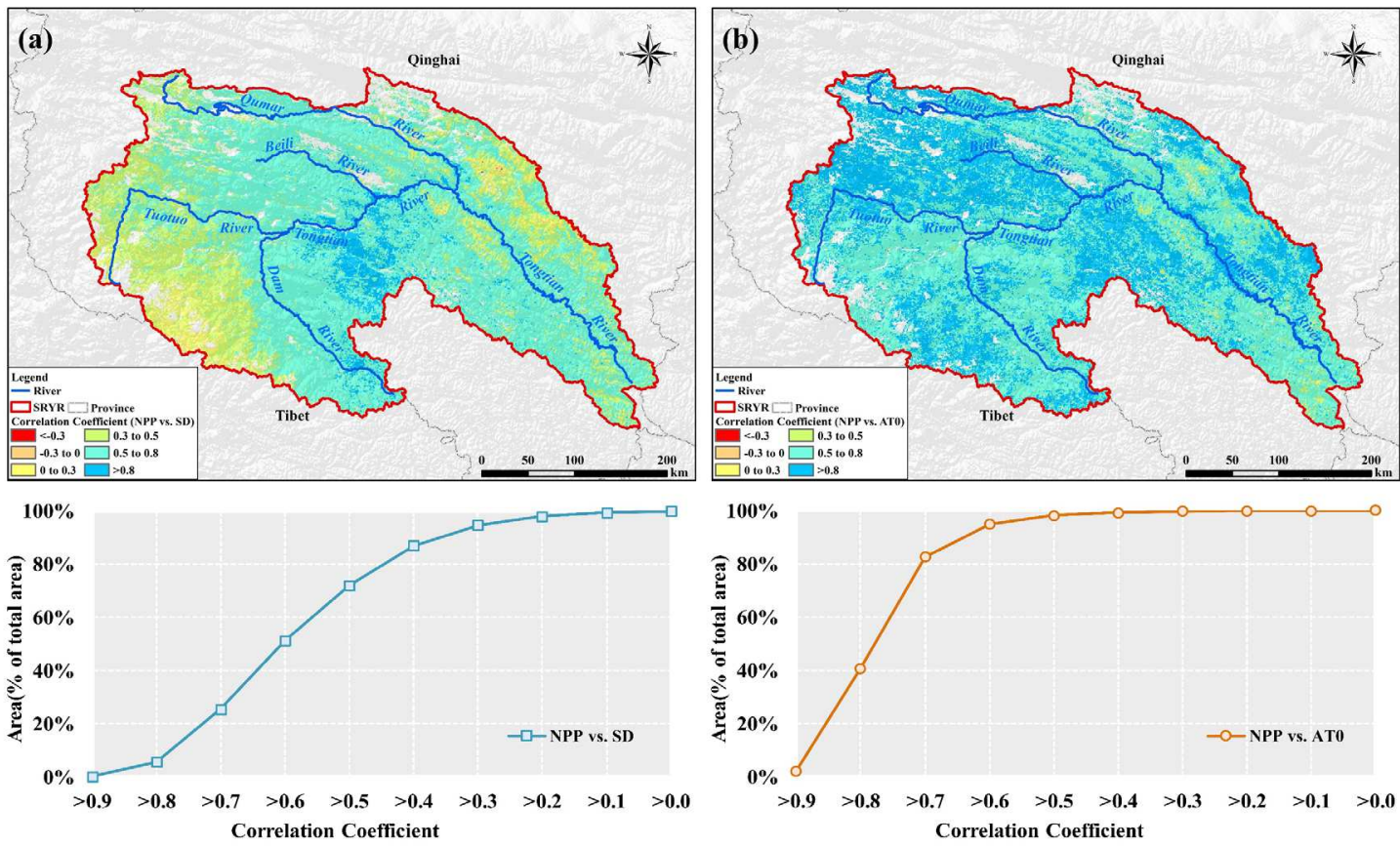

Fig.11 Correlation Coefficient between NPP and soil water deficit (a) / accumulated temperature (b) 

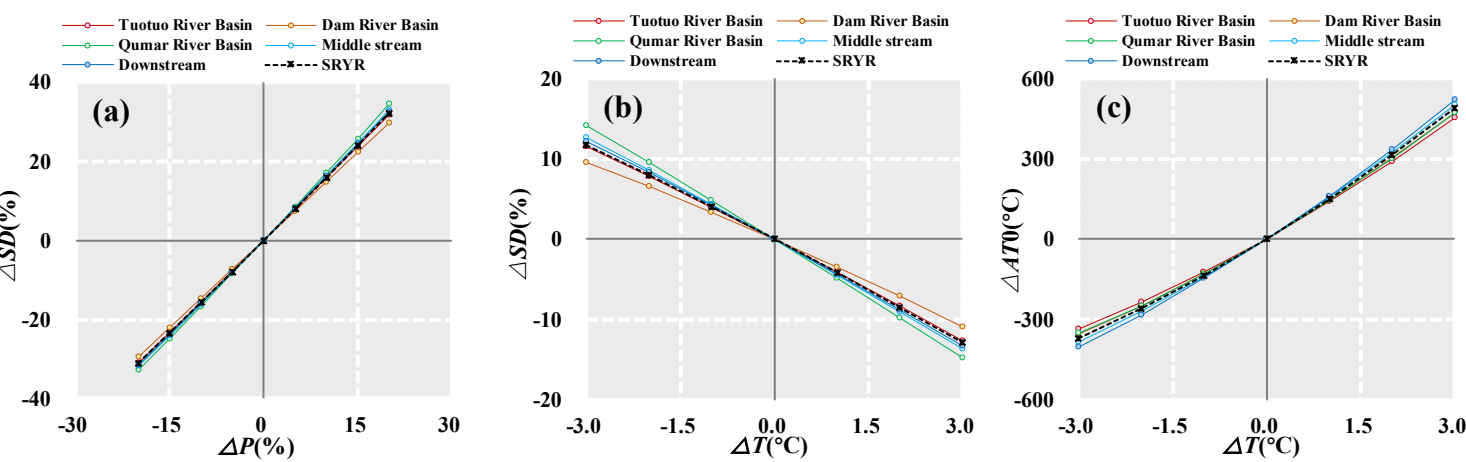

Fig.12 Sensitivity on soil water deficit/ accumulated temperature due to precipitation and temperature change in the SRYR: (a) soil water deficit affected by precipitation change; (b) soil water deficit affected by temperature change; (c) accumulated temperature affected by temperature change
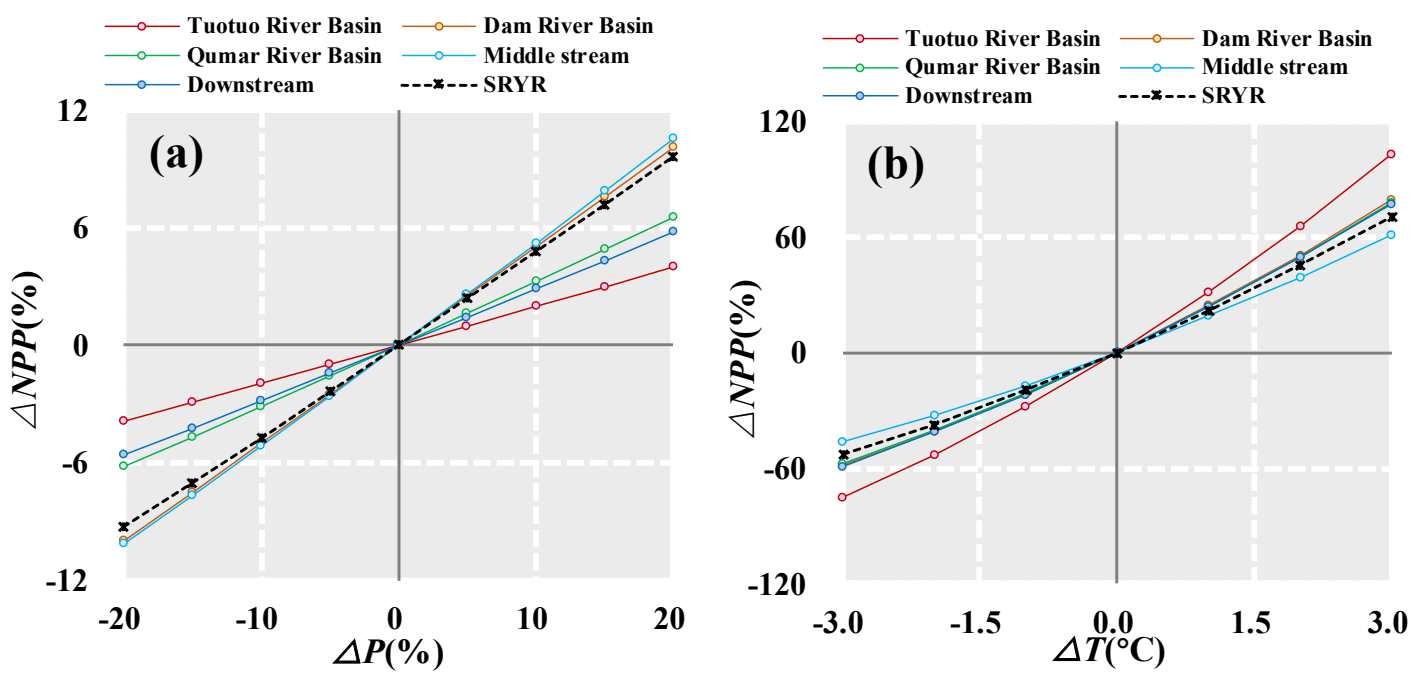

Fig.13 Sensitivity on NPP due to precipitation and temperature change in the SRYR

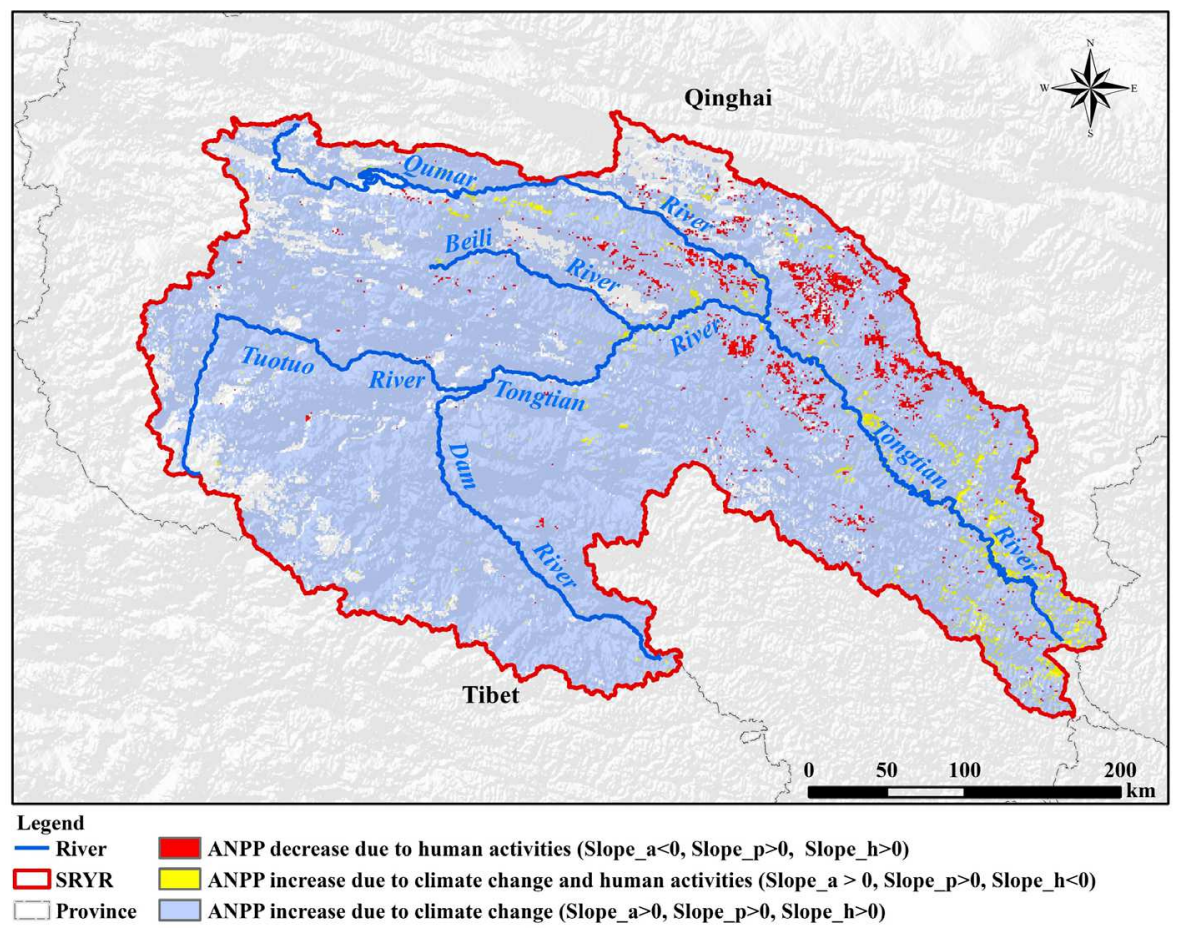

Fig. 14. Spatial distribution of different driving forces of changes in NPP from 2000 to 2014 in the SRYR 
Figures

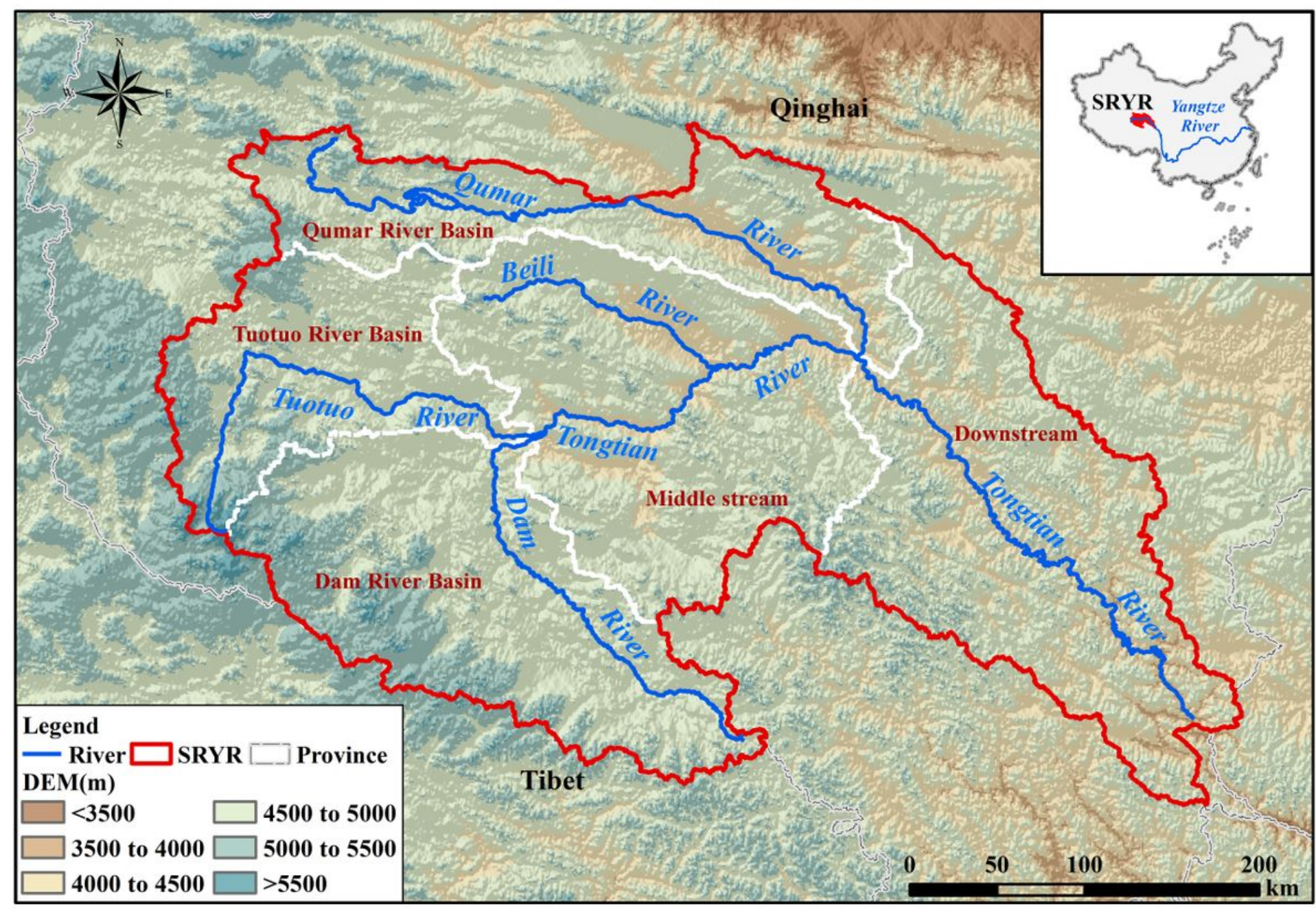

\section{Figure 1}

Runoff coefficients for different slopes. Note: The designations employed and the presentation of the material on this map do not imply the expression of any opinion whatsoever on the part of Research Square concerning the legal status of any country, territory, city or area or of its authorities, or concerning the delimitation of its frontiers or boundaries. This map has been provided by the authors. 


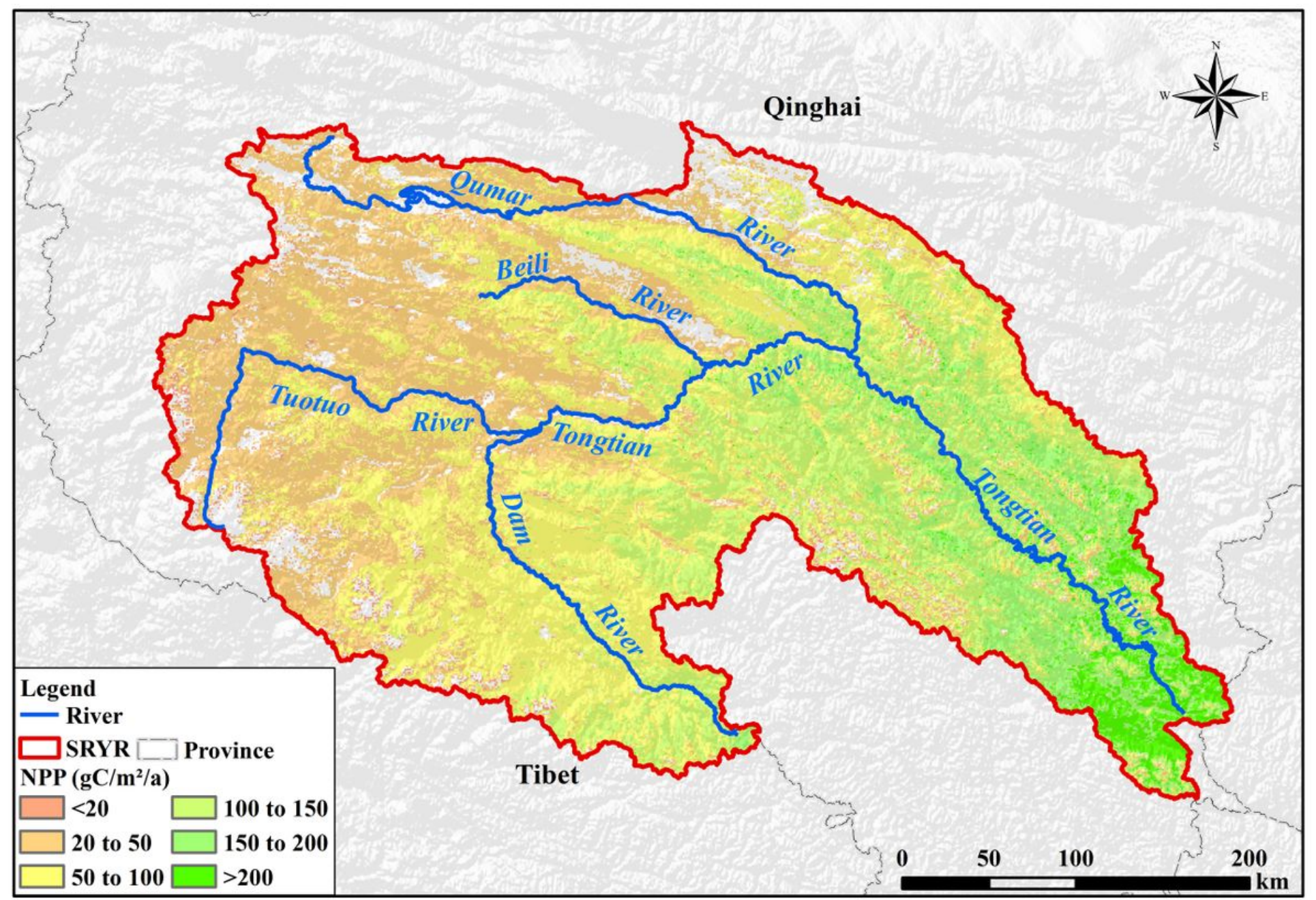

Figure 2

The spatial distribution of multi-year average NP. Note: The designations employed and the presentation of the material on this map do not imply the expression of any opinion whatsoever on the part of Research Square concerning the legal status of any country, territory, city or area or of its authorities, or concerning the delimitation of its frontiers or boundaries. This map has been provided by the authors. 
400

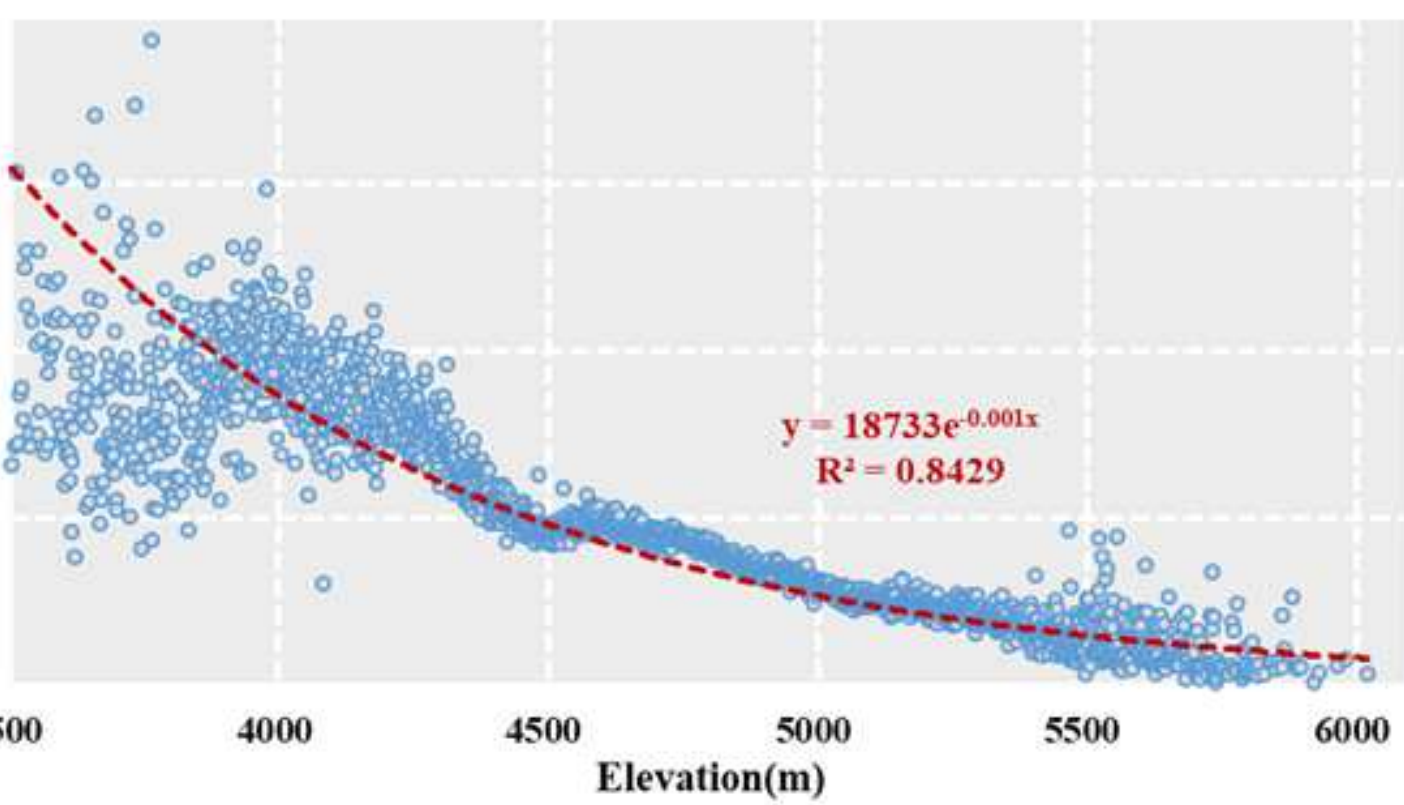

\section{Figure 3}

Average NPP in different elevation

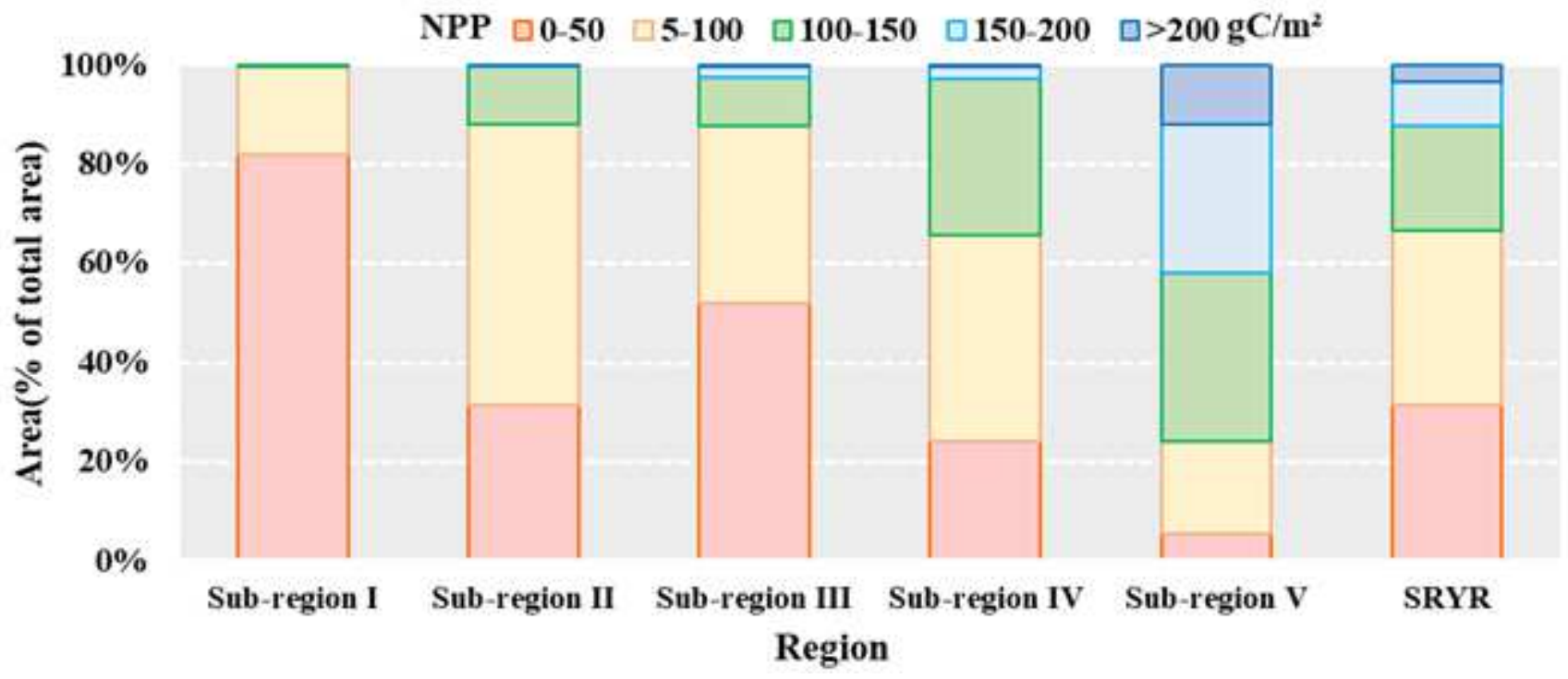

Figure 4

Area percentages of regions with different grades in average annual NPP* *Note: Sub-region I to V represent Tuotuo River Basin, Dam River Basin, Qumar River Basin, Middle stream and Downstream, respectively. 


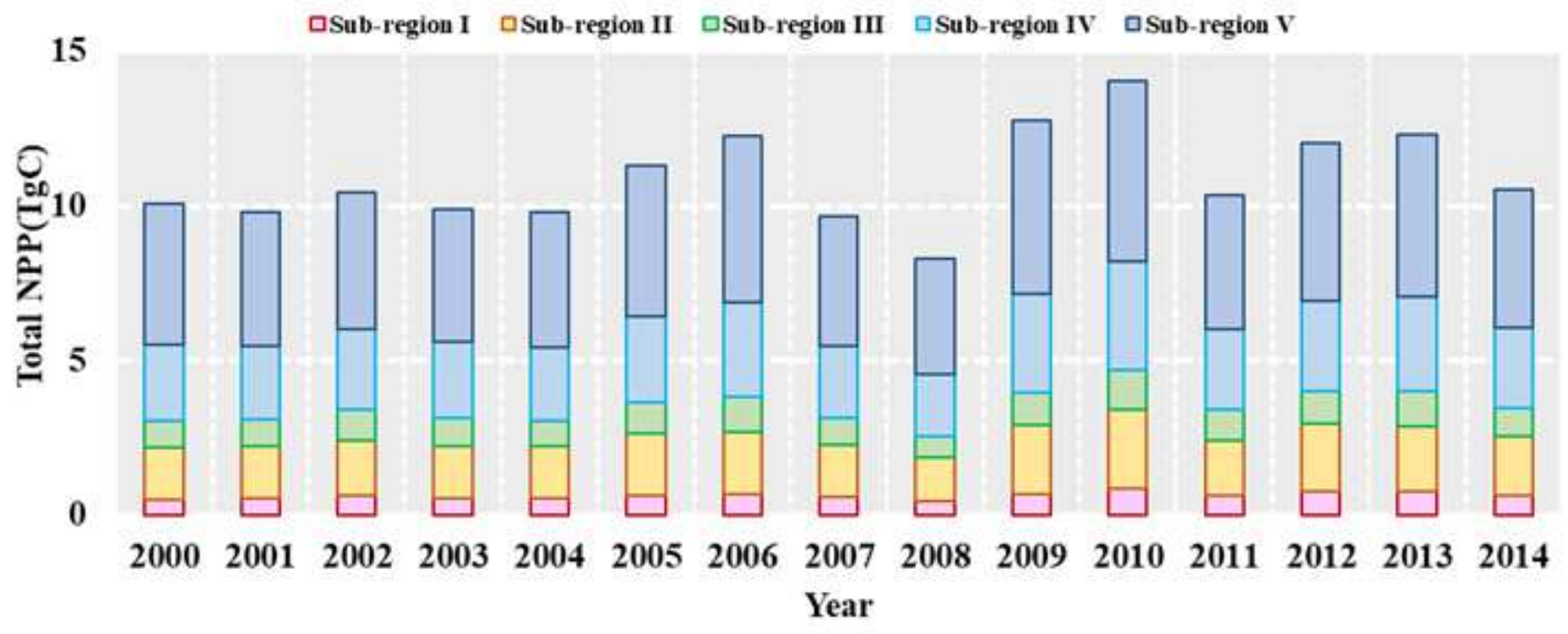

Figure 5

Changes in annual NPP in the SRYR* *Note: Sub-region I to V represent Tuotuo River Basin, Dam River Basin, Qumar River Basin, Middle stream and Downstream, respectively.

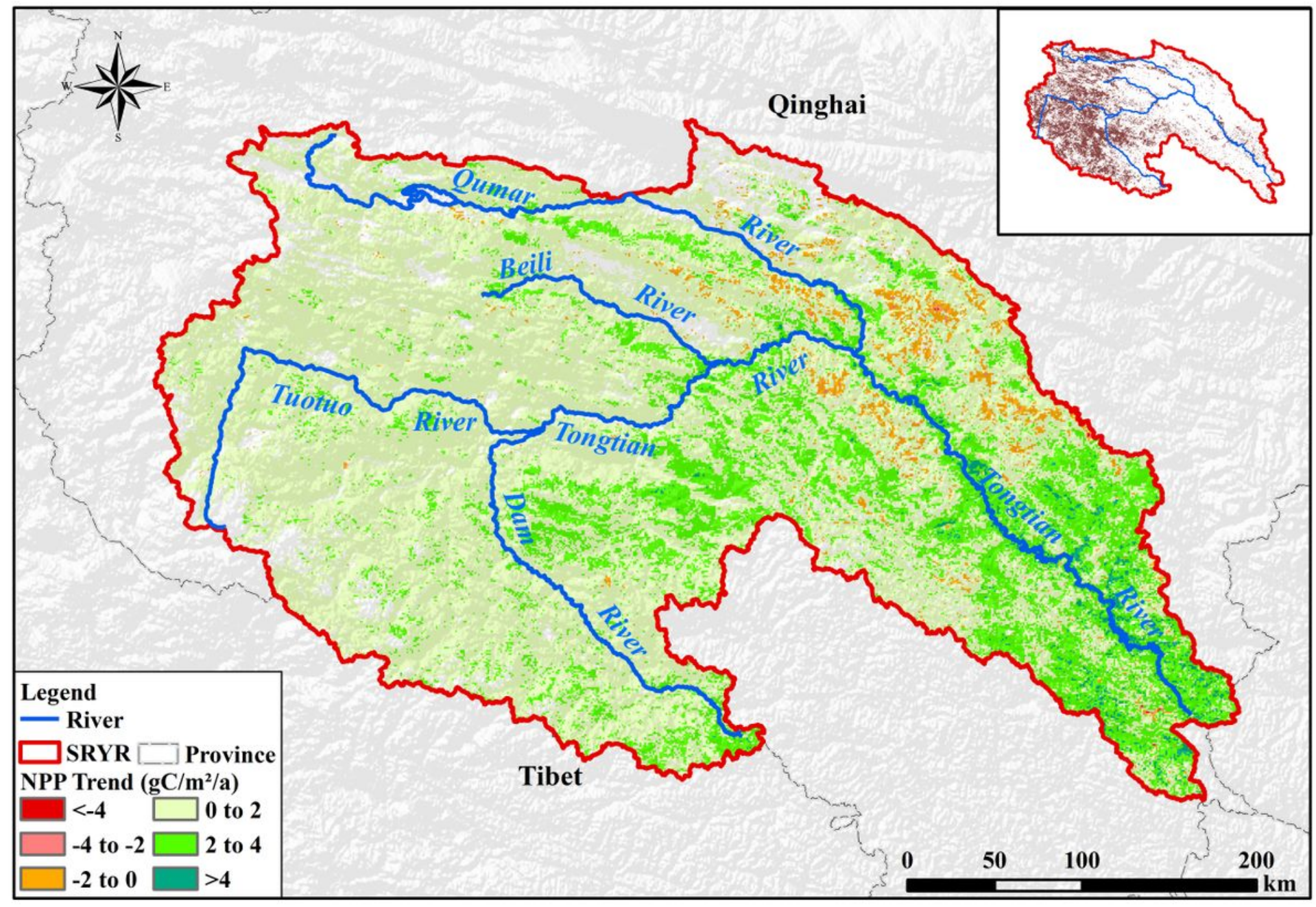


Figure 6

Spatial trends of NPP in SRYR. The small inset map in Fig. 6 shows that the spatial pattern of trend significance levels marked by " $p$ ". The region filled in white is non-significant at $p>0.05$. Note: The designations employed and the presentation of the material on this map do not imply the expression of any opinion whatsoever on the part of Research Square concerning the legal status of any country, territory, city or area or of its authorities, or concerning the delimitation of its frontiers or boundaries. This map has been provided by the authors.
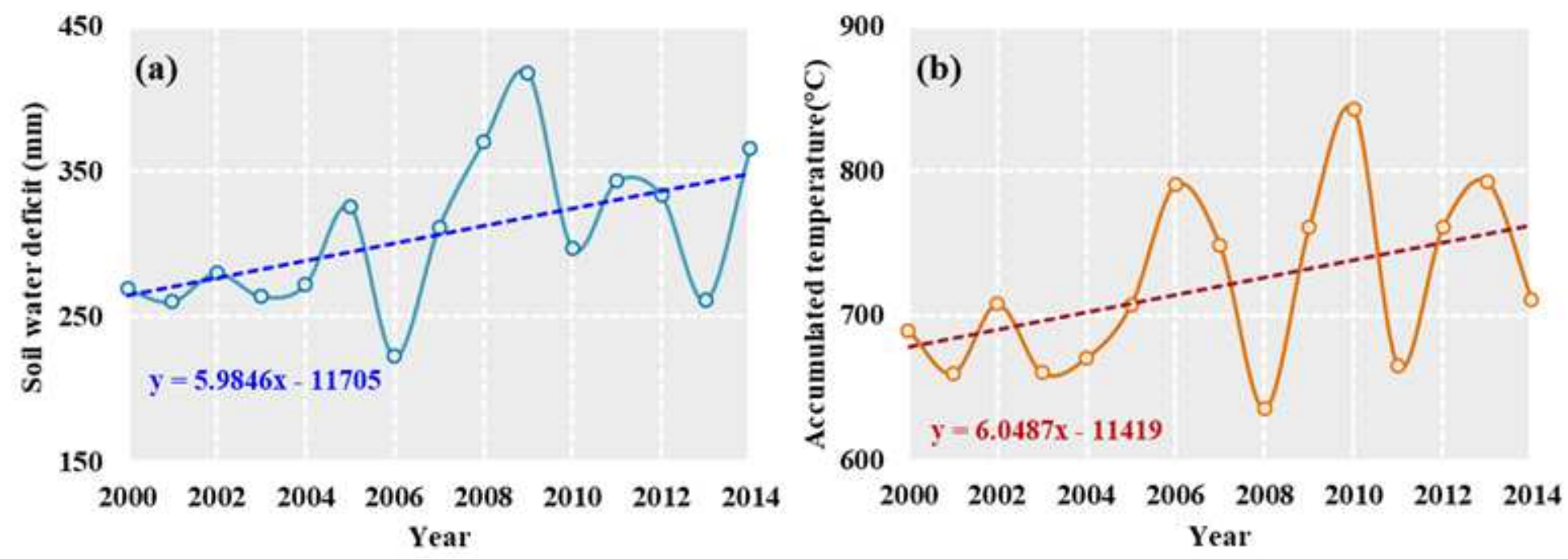

Figure 7

Changes in annual effective precipitation (a) and accumulated temperature (b) in the SRYR 

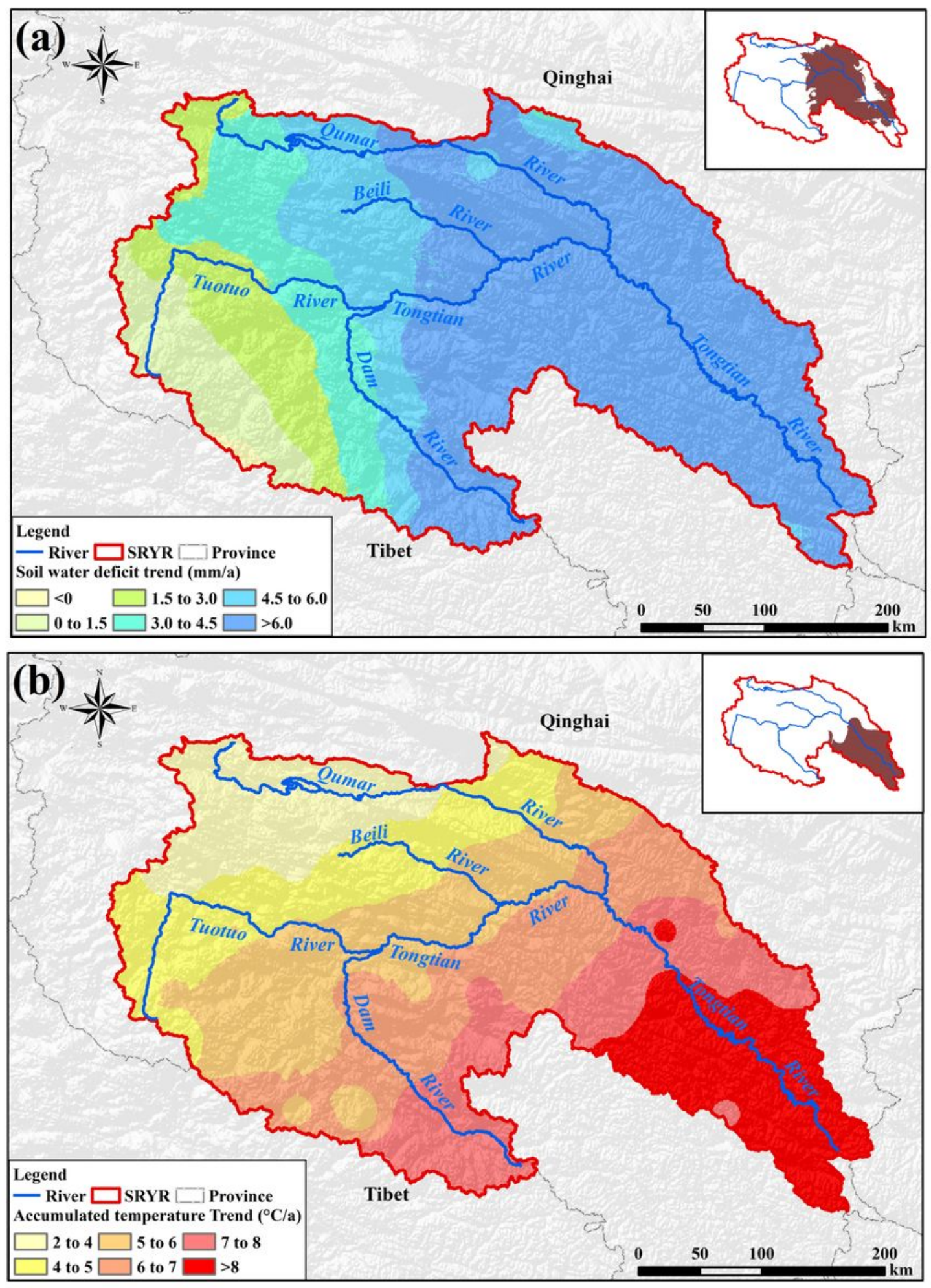

\section{Figure 8}

Spatial trends of soil water deficit and accumulated temperature in SRYR. The small inset map in Fig. 8 shows that the spatial pattern of trend significance levels marked by " $p$ ". The region filled in white is nonsignificant at $p>0.05$. Note: The designations employed and the presentation of the material on this map do not imply the expression of any opinion whatsoever on the part of Research Square concerning the 
legal status of any country, territory, city or area or of its authorities, or concerning the delimitation of its frontiers or boundaries. This map has been provided by the authors.

1.0

(a)

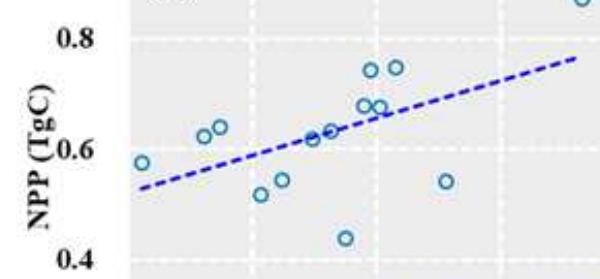

0.4

$y=0.0009 x+0.3869$

0.2

$\begin{array}{lllll}150 & 225 & 300 & 375 & 450\end{array}$ Soil water deficit at 1-year lag (mm)

3.6

(d)

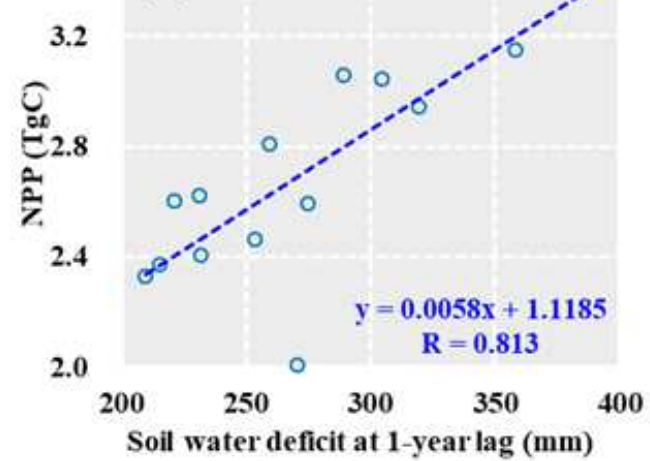

2.6

(b)

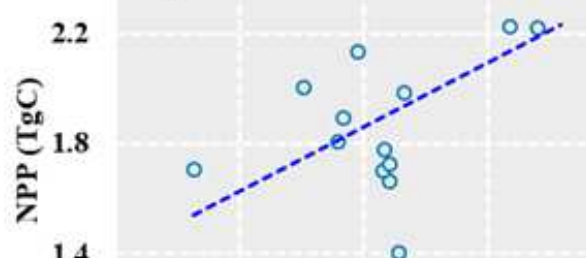

1.4

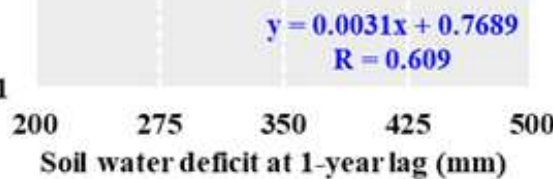

6.0

(e)

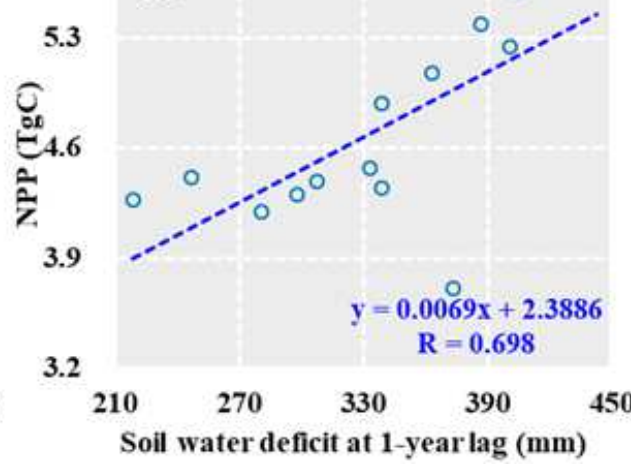

1.4

(c)

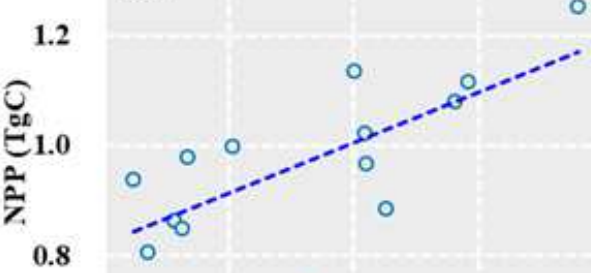

0.6

$y=0.0018 x+0.5656$ $\mathrm{R}=\mathbf{0 . 7 0 0}$

$\begin{array}{lllll}140 & 190 & 240 & 290 & 340\end{array}$ Soil water deficit at 1-year lag (mm)

16

(f)

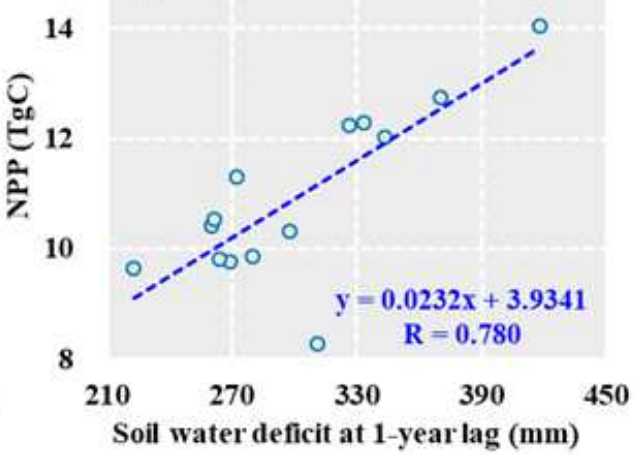

\section{Figure 9}

Correlation between NPP and soil water deficit: (a) Tuotuo River Basin; (b) Dam River Basin;(c) Qumar River Basin;(d) Middle stream; (e) Downstream and (f) SRYR 
1.0

(a)

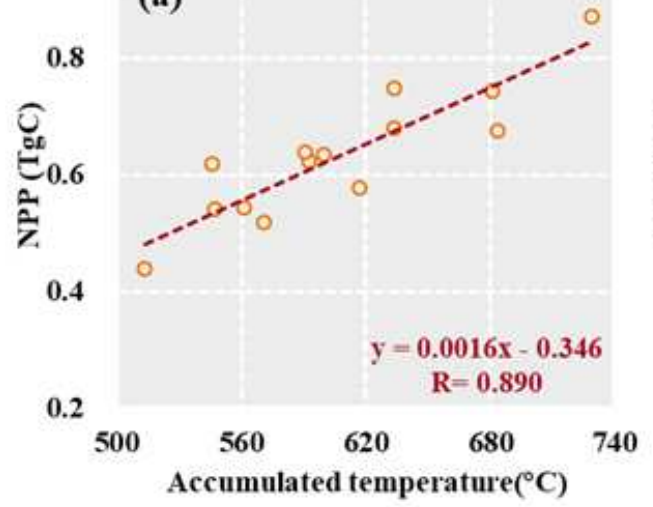

3.6

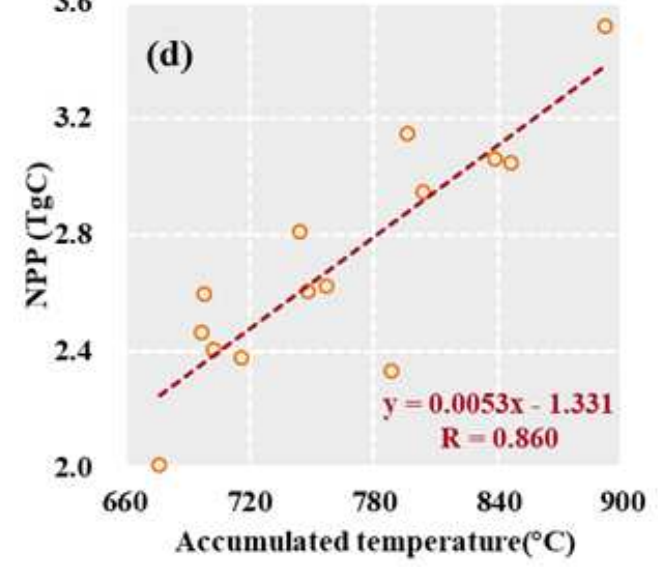

2.7

(b)

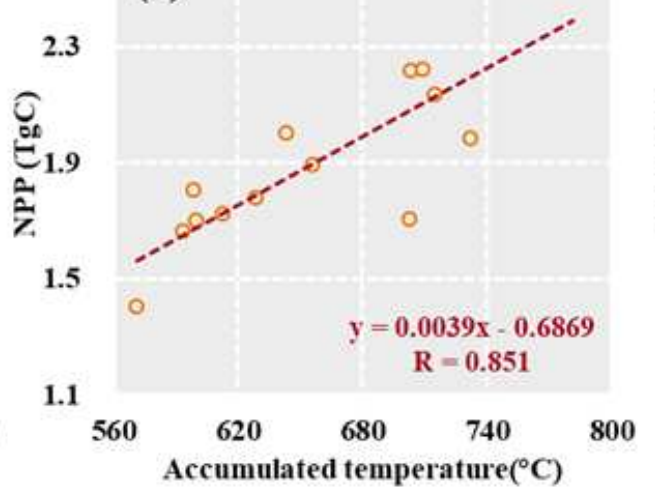

6.0

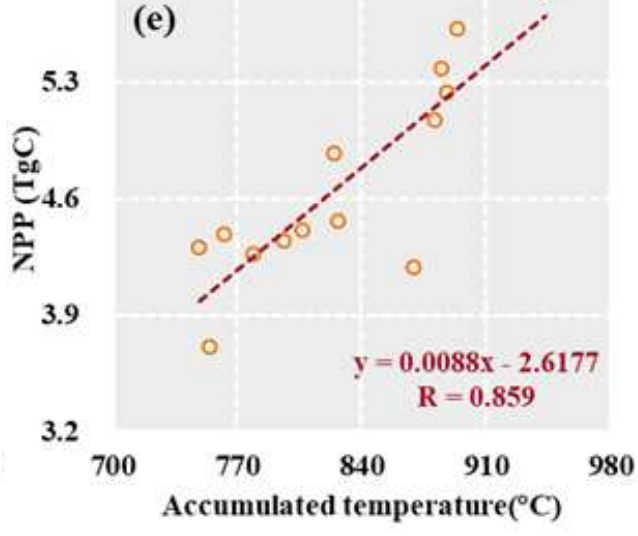

(e)
1.4

(c)

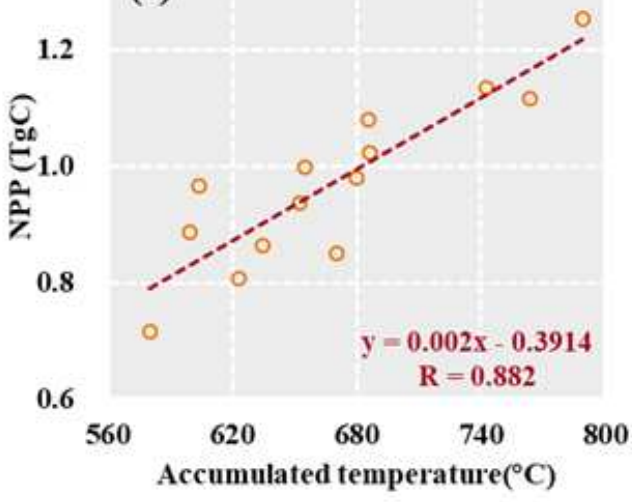

16

\section{(f)}

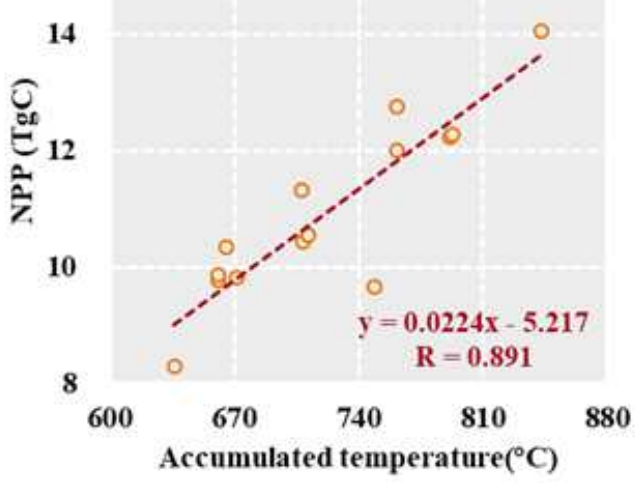

Figure 10

Correlation between NPP and accumulated temperature: (a) Tuotuo River Basin; (b) Dam River Basin; (c) Qumar River Basin; (d) Middle stream; (e) Downstream and (f) SRYR 

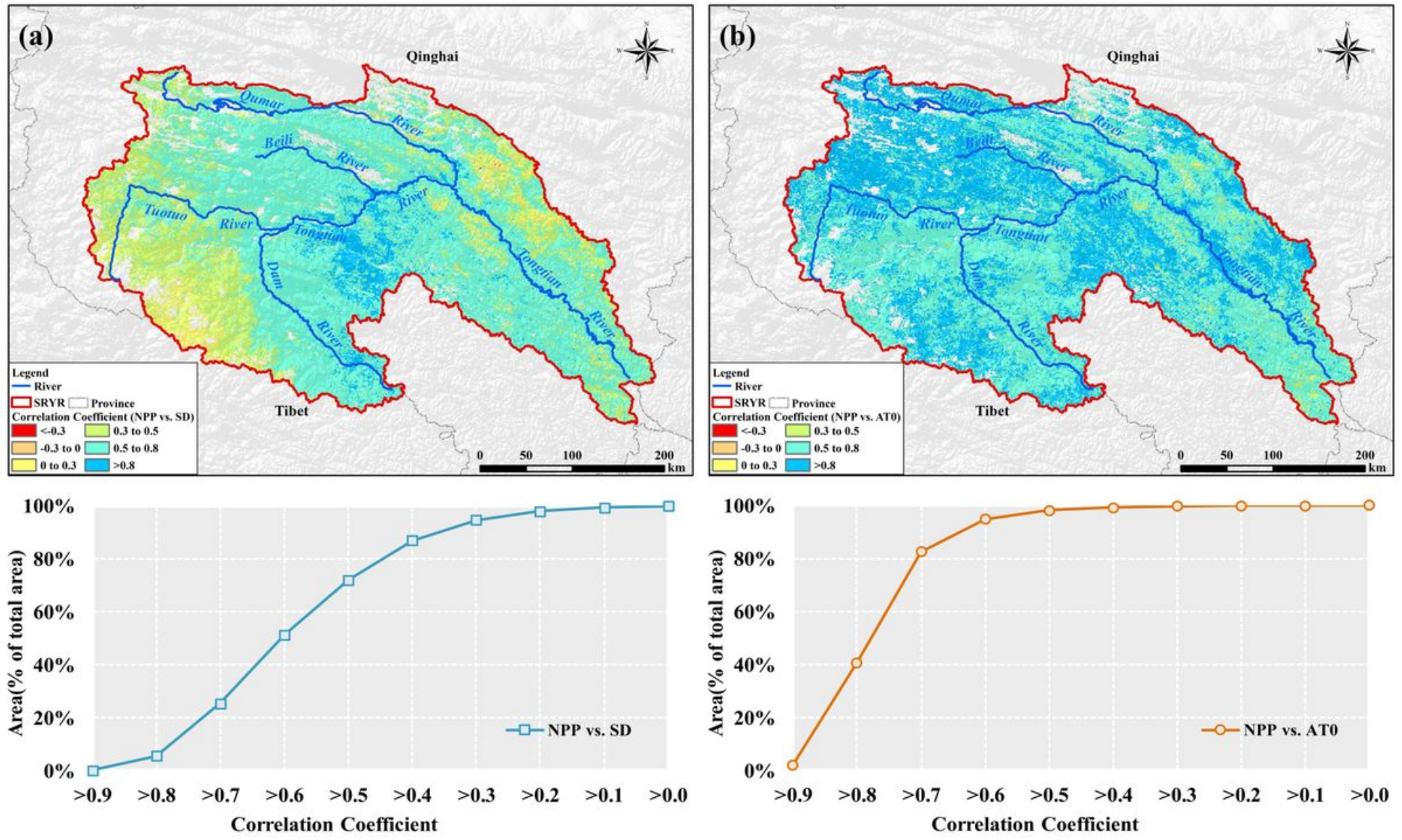

\section{Figure 11}

Correlation Coefficient between NPP and soil water deficit (a) / accumulated temperature (b). Note: The designations employed and the presentation of the material on this map do not imply the expression of any opinion whatsoever on the part of Research Square concerning the legal status of any country, territory, city or area or of its authorities, or concerning the delimitation of its frontiers or boundaries. This map has been provided by the authors.
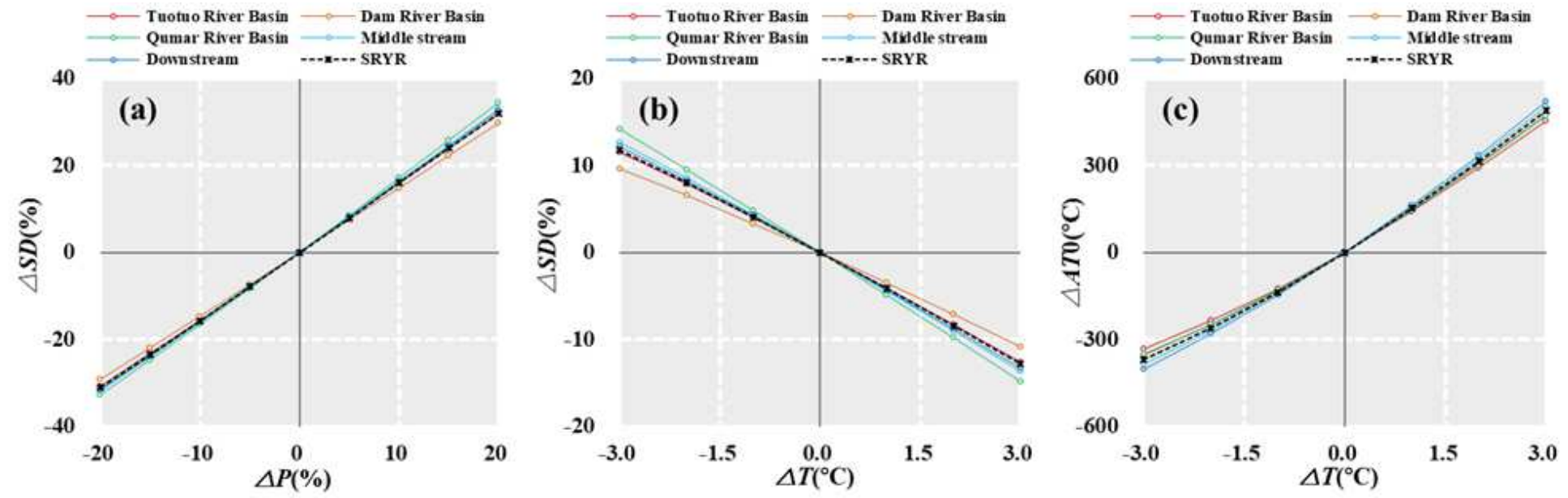

Figure 12 
Sensitivity on soil water deficit/ accumulated temperature due to precipitation and temperature change in the SRYR: (a) soil water deficit affected by precipitation change; (b) soil water deficit affected by temperature change; (c) accumulated temperature affected by temperature change
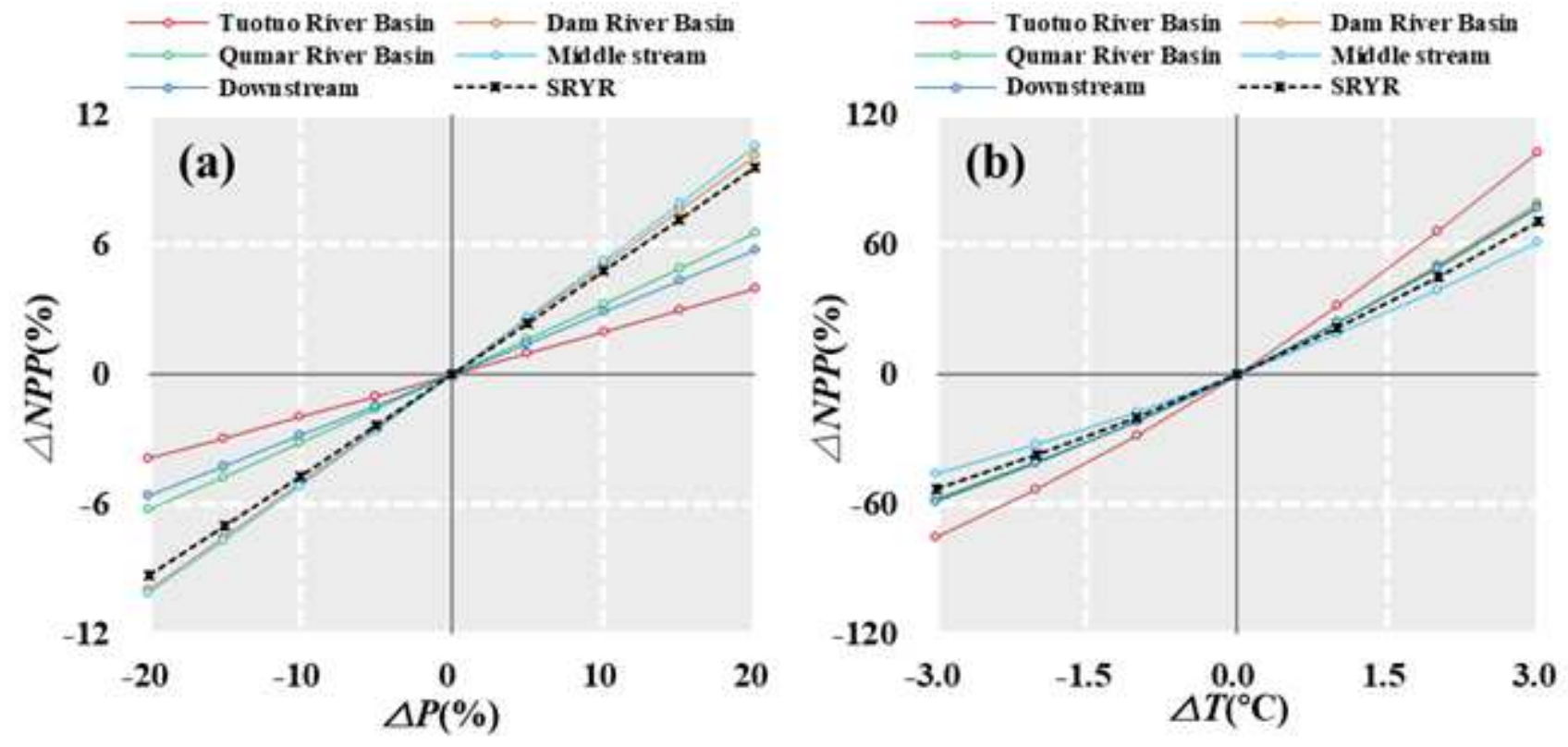

Figure 13

Sensitivity on NPP due to precipitation and temperature change in the SRYR 


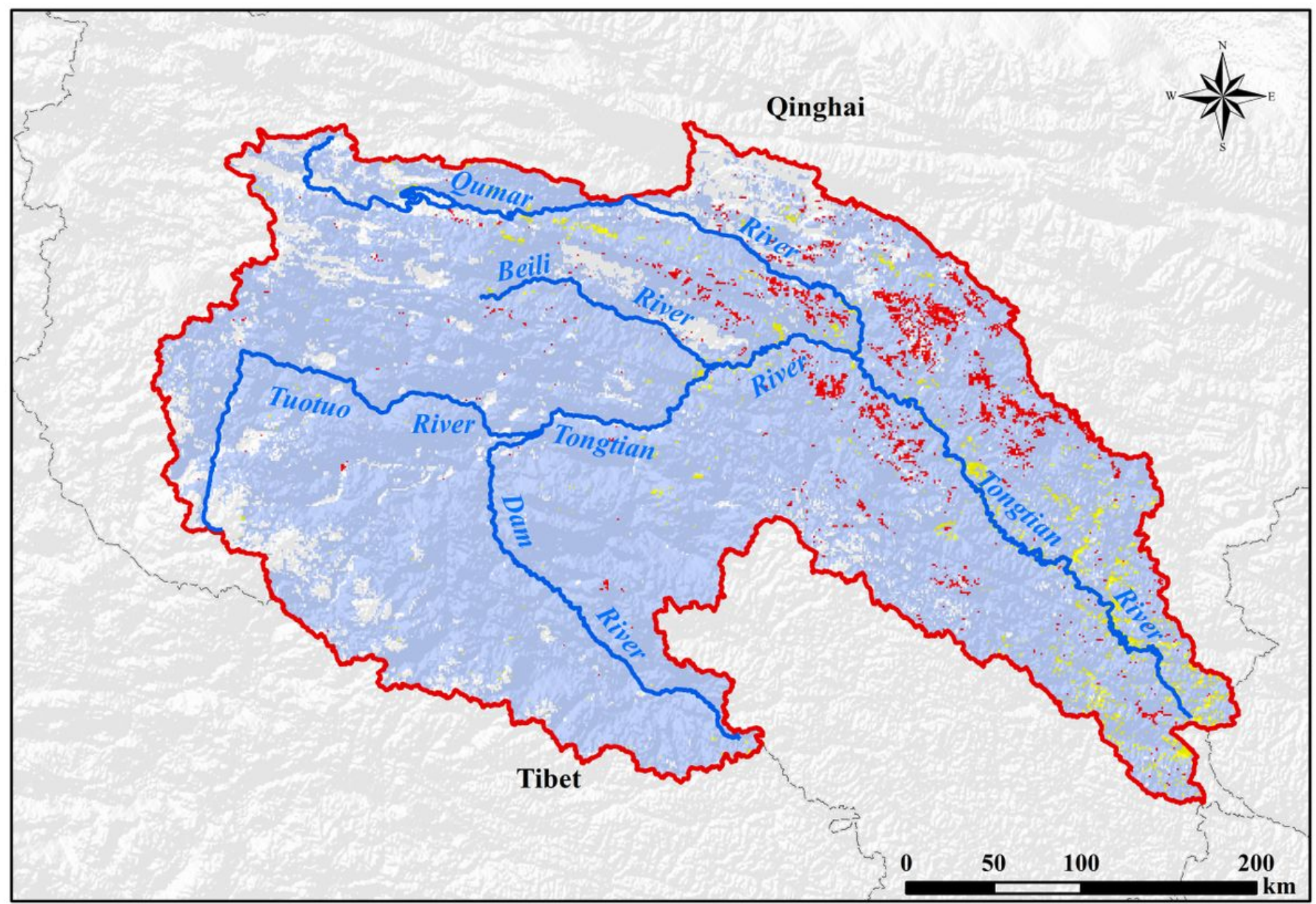

Legend

River

ANPP decrease due to human activities (Slope_a $<0$, Slope_p $>0$, Slope_h $>0$ )

SRYR

ANPP increase due to climate change and human activities (Slope_a $>0$, Slope_p $>0$, Slope_h $<0$ )

Province

ANPP increase due to climate change (Slope_a $>0$, Slope_p $>0$, Slope_h $>0$ )

\section{Figure 14}

Spatial distribution of different driving forces of changes in NPP from 2000 to 2014 in the SRYR. Note: The designations employed and the presentation of the material on this map do not imply the expression of any opinion whatsoever on the part of Research Square concerning the legal status of any country, territory, city or area or of its authorities, or concerning the delimitation of its frontiers or boundaries. This map has been provided by the authors. 